\title{
Review \\ Quorum-Sensing Inhibition by Gram-Positive Bacteria
}

\author{
Evgeniya V. Prazdnova ${ }^{1, * \mathbb{C}}$, Andrey V. Gorovtsov ${ }^{1}$, Nikita G. Vasilchenko ${ }^{1} \mathbb{D}$, Maxim P. Kulikov ${ }^{1}$, \\ Varvara N. Statsenko ${ }^{1}$, Anna A. Bogdanova ${ }^{2}$, Alexandr G. Refeld ${ }^{3}$, Yaroslav A. Brislavskiy ${ }^{1}$, \\ Vladimir A. Chistyakov ${ }^{1,4}\left(\mathbb{D}\right.$ and Michael L. Chikindas ${ }^{4,5,6}(\mathbb{B}$
}

1 Academy of Biology and Biotechnology, Southern Federal University, 344090 Rostov-on-Don, Russia; avgorovcov@sfedu.ru (A.V.G.); nvasilchenko@sfedu.ru (N.G.V.); makkulikov@sfedu.ru (M.P.K.); varstacenko@sfedu.ru (V.N.S.); brislavsky@sfedu.ru (Y.A.B.); vladimirchi@sfedu.ru (V.A.C.)

2 Evolutionary Biomedicine Laboratory, SCAMT Institute, ITMO University, 125993 Saint Petersburg, Russia; aaaabogdanova@gmail.com

3 Cell Biophysics Laboratory, SCAMT Institute, ITMO University, 125993 Saint Petersburg, Russia; agrefeld@mail.ru

4 Center for Agrobiotechnology, Don State Technical University, 344002 Rostov-on-Don, Russia; tchikind@sebs.rutgers.edu

5 Health Promoting Naturals Laboratory, School of Environmental and Biological Sciences, Rutgers State University, New Brunswick, NJ 08854, USA

6 Department of General Hygiene, I.M. Sechenov First Moscow State Medical University, 119991 Moscow, Russia

* Correspondence: prazdnova@sfedu.ru

Citation: Prazdnova, E.V.; Gorovtsov, A.V.; Vasilchenko, N.G.; Kulikov,

M.P.; Statsenko, V.N.; Bogdanova,

A.A.; Refeld, A.G.; Brislavskiy, Y.A.;

Chistyakov, V.A.; Chikindas, M.L.

Quorum-Sensing Inhibition by

Gram-Positive Bacteria.

Microorganisms 2022, 10, 350.

https://doi.org/10.3390/

microorganisms 10020350

Academic Editor: Nicole

Hugouvieux-Cotte-Pattat

Received: 14 December 2021

Accepted: 28 January 2022

Published: 3 February 2022

Publisher's Note: MDPI stays neutral with regard to jurisdictional claims in published maps and institutional affiliations.

Copyright: () 2022 by the authors. Licensee MDPI, Basel, Switzerland. This article is an open access article distributed under the terms and conditions of the Creative Commons Attribution (CC BY) license (https:// creativecommons.org/licenses/by/ $4.0 /)$.

\begin{abstract}
The modern paradigm assumes that interspecies communication of microorganisms occurs through precise regulatory mechanisms. In particular, antagonism between bacteria or bacteria and fungi can be achieved by direct destruction of the targeted cells through the regulated production of antimicrobial metabolites or by controlling their adaptive mechanisms, such as the formation of biofilms. The quorum-quenching phenomenon provides such a countermeasure strategy. This review discusses quorum-sensing suppression by Gram-positive microorganisms, the underlying mechanisms of this process, and its molecular intermediates. The main focus will be on Grampositive bacteria that have practical applications, such as starter cultures for food fermentation, probiotics, and other microorganisms of biotechnological importance. The possible evolutionary role of quorum-quenching mechanisms during the development of interspecies interactions of bacteria is also considered. In addition, the review provides possible practical applications for these mechanisms, such as the control of pathogens, improving the efficiency of probiotics, and plant protection.
\end{abstract}

Keywords: quorum-sensing; quorum-quenching; gram-positive bacteria

\section{Introduction: Quorum-Sensing and Quorum-Quenching as Mechanisms of Interspecies Interactions}

Quorum-sensing (QS) is an intraspecies interaction mechanism characteristic of bacteria and fungi [1]. Quorum-quenching (QQ), or interruption of QS signaling, is a mechanism of interspecies and even cross-kingdom interactions. Bacteria use it as a mechanism of antagonism, while in eukaryotes it is used for protection against pathogens [2]. In a broad sense, QQ refers to any disruption of intercellular communication.

The interruption of a QS signal can occur in several ways: (1) stopping the synthesis of signaling molecules; (2) inactivation or enzymatic destruction of signaling molecules, preventing accumulation to a threshold value; (3) interference with the binding of signal receptors in a bacterial cell or competition with signal molecules-receptor analogs; and (4) blocking target genes that should have been triggered by the QS signal [3,4].

Disruption of the signaling molecules' synthesis can be achieved by inhibiting the enzymes involved in this process, such as the acyl chain (acyl carrier protein, ACP) and 
S-adenosylmethionine synthase [4], or, for example, by blocking the Lux system, which serves as a fundamental model for Gram-negative proteobacterial QS systems [5].

Disruption of the signaling molecules' interaction with receptors can be caused by agonists (analogs of signaling molecules competing with them for receptors) and antagonists (receptor blockers). This mechanism is characteristic of cross-quenching of autoinducers (signaling molecules that are produced as a reaction to changes in population density of bacteria) when each autoinducing peptide (AIP) activates its related receptor but inhibits the activation of all others by competitive binding to foreign receptors. This mechanism is typical, for example, for intraspecific competition between different groups of Staphylococcus aureus [4].

The destruction of QS signaling molecules is an enzymatic process. The most wellstudied mechanism is the degradation of the autoinducer acyl-homoserine lactone (AHL). This process involves AHL acylases and AHL lactonases, which cut the amide linkage of AHLs and destroy the lactone ring, respectively [5], as well as AHL -oxidoreductase, and AHL-oxidase, which oxidize signaling molecules [6]. The best-studied mechanism is the degradation of AHL by lactonases which are produced by many types of microorganisms. AHL lactonases are grouped into two clusters: the AiiA cluster (produced by Bacillus) and AttM (produced by Gram-negative bacteria) [4,5].

From an evolutionary point of view, there are two reasons why bacteria would develop QQ mechanisms. First, it is the mechanism of antagonism with competitors; secondly, it is the utilization of QS signals by bacteria, both to reuse resources and to regulate and "fine-tune" the processes regulated by QS signaling [4].

In addition, enzymes active against QS signals, such as AHL lactonases, have other properties that are beneficial for bacteria, namely, the destruction of toxins. In particular, Bacillus lactonases can inactivate mycotoxins such as aflatoxin B1 [7] and zearalenone. Thus, in some cases, QQ activity may be a product of parallel evolutionary processes.

Strategies for the practical use of compounds and strains capable of QQ exist in medicine, animal husbandry, and crop production. Since the manifestation of pathogenicity factors [8], antibiotic resistance [9], and other essential properties of bacteria depend on the work of QS systems, making them the target of therapy seems to be a promising approach.

This work aims to systematize the data on the mechanisms by which Gram-positive bacteria interrupt the QS signals of other bacteria. Among the Gram-positive groups, many probiotic microorganisms enter into a mutually beneficial symbiotic relationship with the host. Studying the mechanisms of their interaction with other representatives of the microbiota may shed light on some aspects of their probiotic activity. The antagonism between probiotic strains and pathogenic microorganisms may be due, in part, to the QQ effect.

\section{Role of QS in Pathogenicity and Antimicrobial Resistance}

The discovery of cell-to-cell communication between bacteria has led to the realization that bacteria can coordinate crucial metabolic activities. For example, in many pathogens, the QS process reduces the host immune response by delaying the production of virulence factors in pathogenic bacteria until the population density becomes sufficient to overcome the host's defense mechanisms. It is now known that a significant portion of the bacterial genome $(4-10 \%)$ and proteome $(\geq 20 \%)$ is influenced by QS signaling processes. This means that QS is a mechanism used by pathogenic bacteria not only for controlling the production of virulence factors but also for adapting to the metabolic needs for life in the community [8].

\subsection{QS of Gram-Negative Bacteria}

The most studied quorum sensing system among Gram-negative bacteria is the homologous LuxR-LuxI system and related signaling molecules: $\mathrm{N}$-acyl homoserine lactones (AHL). It is similar to the system first studied in the marine bacterium Vibrio fischeri. The vast majority of Gram-negative quorum-sensing systems that have been studied so far use 
$\mathrm{N}-\mathrm{AHL}$ as signaling molecules. At sufficiently high concentrations, these molecules can bind to a transcription activator or R-protein and activate them, which, in turn, induces the expression of target genes [8]. It is becoming apparent that, in addition to AHL, alternative signaling molecules exist in Gram-negative bacteria. For example, the plant pathogen Ralstonia solanacearum produces 3-hydroxypalmitic acid methyl ester as a signaling molecule, which, together with AHL, is used to regulate virulence [10]. Xanthomonas campestris, the causative agent of black rot in cabbage, produces a diffusable extracellular factor that has not yet been chemically characterized but is not an AHL [11]. In Pseudomonas aeruginosa, a third autoinducer was identified, designated PQS (Pseudomonas Quinolone Signal), which differs from two other AHLs produced by this organism [12]. Butyrolactones were isolated from culture supernatants of Pseudomonas aureofaciens, and a new family of signaling compounds identified as diketopiperazines (DKP) was found in cell-free supernatants of P. aeruginosa, P. fluorescens, P. alcaligenes, Enterobacter agglomerans, and Citrobacter [13].

\subsubsection{QS in P. aeruginosa}

Among pathogenic bacteria, P. aeruginosa is perhaps the best characterized in terms of its regulated virulence factors and the role that QS plays in pathogenicity. Classified as an opportunistic pathogen, P. aeruginosa infections are most common in people with weakened immune systems, such as those with cancer or AIDS, or those with impaired normal barriers caused by burns, persistent medical devices, or long-term use of broad-spectrum antibiotics. $P$. aeruginosa possesses a wide range of both cell-associated and extracellular virulence factors. The expression of many extracellular factors is not constitutive but depends on cell density, with the maximum production of proteolytic enzymes occurring during the late logarithmic and early stationary growth phases. It has been shown that two interconnected QS sensory systems are involved in virulence, biofilm development, and many other processes in P. aeruginosa. The first system (Las) consists of a lasI-encoded acyl-HSL synthase and a transcriptional activator encoded by lasR. The second system (Rhl) consists of an acyl-HSL synthase encoded by rhlI and a transcriptional activator encoded by rhlR [14]. Recently, a third LuxR-type protein has been identified called QscR (quorum sensing control repressor). Analysis of the Pseudomonas genome revealed additional genes encoding LasR and RhlR homologs but did not find genes encoding LasI and RhlI homologs. The predicted ORF is 714 nucleotides long and encodes a polypeptide of 27,236 Da. The QscR protein contains two domains characteristic of LuxR-type regulators: an acyl-HSL-binding domain and a DNA-binding domain. It was found that QscR inhibits the transcription of three QS-controlled gene clusters, phz (phenazine), hcn (hydrogen cyanide), and qsc105. This suppression appears to be effective in the logarithmic growth phase [15].

QS in P. aeruginosa regulates the expression of several virulence factors, and this regulation plays a vital role in pathogenicity (Figure 1). This assumption has been confirmed using several different animal models. In a pneumonia model in newborn mice, the las $R$ deficient $P$. aeruginosa strain had a significantly lower virulence than the parental one. Another study used three different infection models, Caenorhabditis elegans (nematode), Arabidopsis thaliana (plant), and lasR-deficient mutant mice obtained by random mutagenesis and showed significantly reduced virulence in all three models. These studies prove that the mentioned genes are associated with QS and contribute to the virulence of P. aeruginosa in different kingdoms $[8,16]$.

\subsubsection{QS in Enterohemorrhagic Escherichia coli O157:H7}

Infection with enterohemorrhagic E. coli O157:H7 (EHEC) can lead to severe gastroenteritis and other extraintestinal manifestations, including fever, meningitis, and sepsis. EHEC also expresses Shiga toxin (Stx) in the gut, whose receptors are also located in the kidney and central nervous system. Stx is a potent inhibitor of protein synthesis and can be systemically absorbed, resulting in hemolytic uremic syndrome (HUS), seizures, cerebral edema, and coma. 


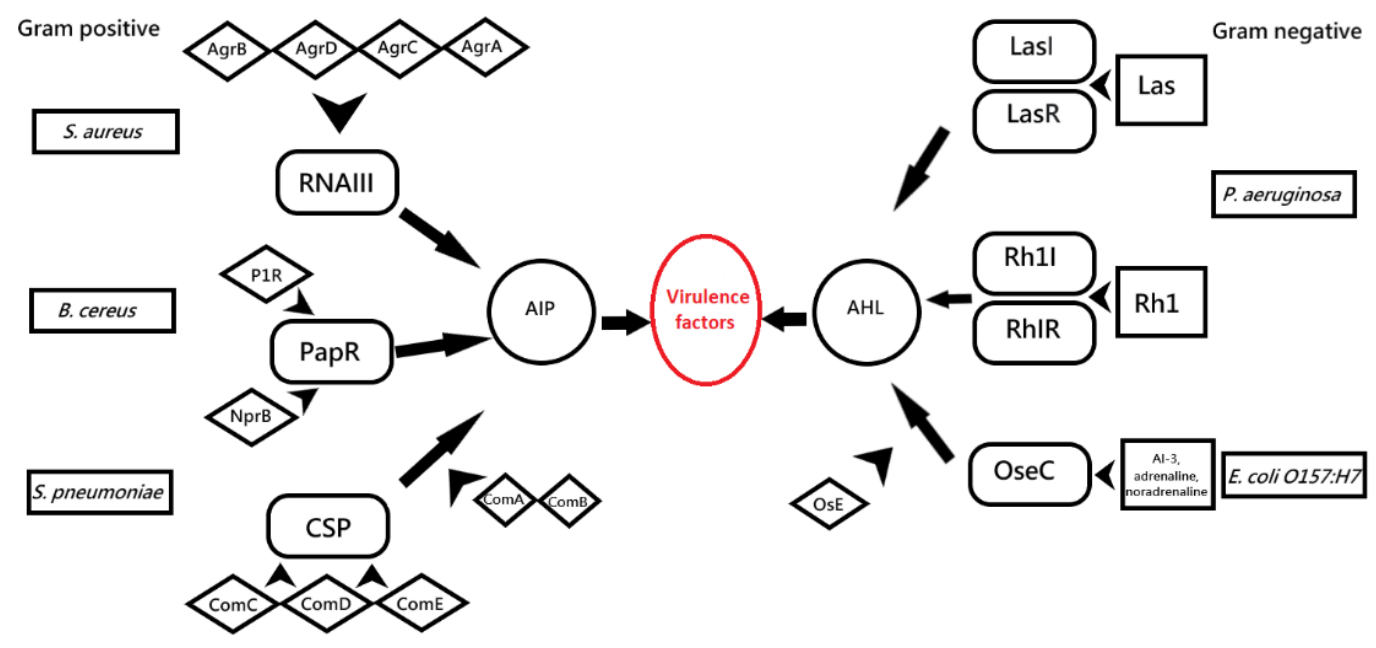

Figure 1. Regulation of QS systems.

There are three signals in EHEC that may activate the transcription of virulence genes: a bacterial aromatic autoinducer (AI-3) produced by the normal microbiota of the gastrointestinal tract and two hormones (adrenaline/norepinephrine) produced by the host. These signaling molecules can activate a sensor associated with QseC, a membranelocalized receptor (sensor kinase, leading to the transcription of virulence genes. QseC also activates the expression of a second gene, qseE, which helps fine-tune the signaling cascade (Figure 1). All these transcriptional events lead to the formation of lesions in the intestine and the production of Stx [17].

\subsection{QS in Gram-Positive Bacteria}

The vast majority of QS-related studies are focused on Gram-negative species of bacteria. However, many Gram-positive pathogens pose a serious health threat and their virulence has been shown to be QS-mediated. For instance, QS is involved in the pathogenesis mechanisms of Bacillus cereus, Streptococcus pneumoniae, and S. aureus [8].

The nature of the signaling molecules used in Gram-positive QS-systems is different from that of Gram-negative organisms. QS systems in Gram-positive bacteria usually use small signal peptides that have undergone post-translational processing. These peptide signals interact with the sensory element of a two-component histidine kinase signaling system. It was found that Gram-positive bacteria have two families of transcription factors, RNPP and Rgg, which have a binding domain. RNPP is a protein family which stands for Rap, NprR, PlcR, and PrgX. This family includes all Gram-positive QS systems which bind directly to their signaling peptide in the recipient cell. RNPP is a critical factor in regulating several processes such as sporulation, conjugation, biofilm formation, and pathogenic responses.

The Rgg (regulator gene of glucosyltransferase) transcription factors directly bind pheromones transported to the cytosol (Figure 1). Rgg-like regulators (a family of transcription factors) are found in most gram-positive bacteria. In different species, the Rgg protein can be a regulator of extracellular glucosyltransferase expression (L. lactis), control antibiotic expression (Streptococcus mutans), or control protein secretion (S. pyogenes) [18]. Thus, Rgg can influence the transcription of natural resource use and provide adaptation to environmental conditions. Due to the different organization of Gram-positive QS-systems, alternative QQ mechanisms are utilized to intercept or block signaling in these species [19].

\subsubsection{QS in S. aureus}

S. aureus is a normal constituent of the microbiota of several ecological niches of the human body, including on the skin and the mucous membranes of the respiratory tract. When epidermal or mucosal barriers are damaged or broken, S. aureus can cause a wide range of diseases, from minor skin infections to life-threatening pneumonia, bacteremia, 
and sepsis. This is particularly prevalent in health care settings, with S. aureus being the leading cause of nosocomial infections [7].

The ability of pathogenic $S$. aureus to cause disease depends on the expression of various adhesion molecules, toxins, and compounds that affect the immune system. QS regulates the expression of genes encoding these virulence factors. S. aureus uses the canonical Gram-positive two-component QS system encoded by the agr locus [19]. The additional gene regulator ( $a g r$ ) system consists of RNA, RNA II, and RNA III transcripts. The RNAII operon system consists of four genes: $\operatorname{agr} B, \operatorname{agrD}, \operatorname{agr} C$, and $\operatorname{agr} A$. The signaling cascade begins with the production of a 46 amino acid peptide encoded by the agrD gene, which is then modified by the integral membrane protein AgrB. The modified peptide acts as a final autoinducing peptide (AIP). AgrA and AgrC together form a two-component system with an AIP binding domain and act as a histidine kinase. Induction of the twocomponent system activates the RNAII operon and acts as a transcription factor for the RNAIII transcript itself [20]. RNAIII has a dual function: it activates the production of $\alpha$-toxin and suppresses the expression of fibronectin-binding proteins A and B, peptide $\mathrm{A}$, coagulase, and other surface proteins. The result of this QS regulatory cascade is the suppression of surface virulence factors (such as peptide A) and an increase in the level of secreted virulence factors (such as alpha toxin) (Figure 1). Another critical component of $S$. aureus virulence is biofilm formation. In S. aureus, the agr system regulates biofilm formation. One interpretation of this finding is that the formation of a biofilm gives S. aureus time to grow to a certain density, at which point it is optimally ready to secrete virulence factors. To facilitate cell proliferation, S. aureus stops biofilm formation and reduces surface proteins and adhesion. This behavior is similar to a strategy used by $V$. cholerae [21]. Concerning weakening the expression of virulence genes, known strategies can be grouped into different categories: (1) inhibition of the catalytic functions of AgrB and SpsB, (2) competitive inhibition of AgrC using natural QSI agents or synthesized analogs of AIP, (3) blocking the activity of histidine kinase, (4) inhibition of AgrA P2/P3 interactions; and (5) inhibition of RNAIII transcription [22].

\subsubsection{QS in Bacillus cereus}

Some strains of $B$. cereus are pathogenic bacteria that can colonize the intestines and produce several virulence factors, including hemolysin, causing abdominal pain and diarrhea. The transcription factor PlcR, along with AIP, regulates the genes for the secretion of the virulence factor in B. cereus. The initiation of the QS signaling pathway begins with the expression of the pap $R$ gene. The translation product of the papR gene is a 48 amino acid peptide (PapR), which is then transported outside the cell by a membrane carrier protein. The PapR peptide is then cleaved by the catalytic activity of protein B (product of the $n p r B$ gene) into four small peptides capable of activating the $p l c R$ gene [23]. The last AIP enters the cell again through the membrane channel protein, binds to the PlcR protein, and stimulates the expression of several genes for the secretion of virulence factors. The plcR gene product also acts as an inhibitor of biofilm formation, but the detailed mechanism is still unclear [24]. However, it was found that inactivation of the $p l c R$ gene reduces the secretion of virulence factors but cannot eliminate virulence factor secretion since several additional systems are involved in QS and the regulation of virulence factors (Figure 1). These additional sensory inputs include sporulation via SpOA P, feeding via CodY, motility via FlhA, and other two-component systems [19].

\subsubsection{QS in Streptococcus pneumoniae}

S. pneumoniae is a pathogenic bacterium that causes pneumonia, otitis media, and meningitis in humans. Like other Gram-positive bacteria, S. pneumoniae also uses a 17-residue signal peptide called competence stimulating peptide (CSP). In general, S. pneumoniae exhibits two gene regulation processes/pathways: early gene expression (regulated by ComE) and late gene expression (regulated by ComX). There are two sets of genes that are expressed over time, and the expression of both sets of genes leads to the development of 
competence. The ComCDE operon plays a decisive role in developing competence and biofilm formation in S. pneumoniae [25]. The comC gene encodes immature CSP molecules in the cell, while the products of the other two genes, ComD and ComE, act as transmembrane receptors for CSP molecules and a response regulator system, respectively. The transformation of immature CSP molecules into active ones is carried out using ComA and ComB. The transmembrane channel protein, an ABC transporter, actively transports CSP molecules outside the cell, acting as an inducer of the QS pathway. The binding of CSP to its ComD receptor transfers the phosphate group to ComE. Activated ComE acts as a transcription factor for several genes such as $\operatorname{com} A B, \operatorname{com} C$, and $\operatorname{comDE}$ (Figure 1). It is also reported that ComE is a transcription factor for the $\operatorname{com} X$ gene. This gene produces sigma factor and ComW, which are necessary for the development of pathogenicity [26].

Although few examples of QQ against streptococci have been found [27], the mechanisms of their QS systems are typical for many pathogens, and it is hoped that the search for QS inhibitors against streptococci will become a promising direction of research in the future.

\subsection{Regulation of Microbial Resistance with QS \\ 2.3.1. Efflux Pumps}

Efflux pumps play an important role in the formation of multidrug resistance in bacteria [28]. The regulatory effect of the QS system on the expression of multidrugresistant pumps is that the expression of the pumps can be regulated, while the QS system itself also depends on the expression level of the pumps. Thus, it was found that in Bacteroides fragilis, when cultivated in the presence of self-induced molecules C6-HSL and C8-HSL, the expression of the efflux pump operon's bmeB increased, and resistance to antibiotics was achieved [29]. It was also found that an autoinducer can activate the multidrug resistance pump MexAB-OprM, developing multidrug resistance in bacteria. As mentioned above, the QS system itself also depends on the level of efflux pump expression. However, some researchers have found that overexpression of the MexCD-OprJ pump turns off the P. aeruginosa QS response [30]. When some efflux pumps (such as the RNDresistance-nodulation-division superfamily) displace the antibiotic from the cell to form drug resistance, self-induced molecules of the QS system can also be displaced from the cell, increasing the concentration of self-induced extracellular molecules, which can exacerbate bacterial infections [28]. This finding suggests that high expression of the efflux pump can further activate the QS system, promote the regulation of the synthesis of the toxin factor of infection and the expression of the efflux pump by the QS system, and increase the infectivity and invasiveness of pathogenic bacteria.

\subsubsection{Biofilms}

Recent studies have shown that most human bacterial infections are associated with biofilms, the formation of which is one of the important reasons why clinical bacterial infections are difficult to treat [31]. It was found that bacterial biofilms can lead to bacterial drug resistance due to penetration restriction, nutritional restriction, and phenotypic mechanisms of drug resistance. The molecular barrier and the biofilm (mostly negatively charged) formed by polysaccharides can prevent or slow down the penetration of certain antibiotics, which is the primary mechanism for limiting permeability. Biofilm development provides resistance to desiccation, oxidative stress, and the action of proteases and antimicrobial agents [19]. In Gram-positive bacteria, the QS system regulates biofilm formation using oligopeptides as signaling molecules that can be recognized by a two-component sensory protein after modification and affect the expression of the target gene through phosphorylation and dephosphorylation of the protein [24].

In general, the regulation of QS systems can be summarized in the following scheme (Figure 1). 


\section{Mechanisms and Metabolites That Are Responsible for QQ in Different Groups}

\subsection{Firmicutes}

\subsubsection{Bacillus}

The most common bacterial strains, including soil bacilli capable of inhibiting biofilm formation, can be found in the rhizosphere of plants, various bodies of water, and other microbial communities. For example, various authors have shown that a high abundance of AHL-degrading bacteria can be found in the rhizosphere of potatoes, mainly belonging to the genera Agrobacterium, Bacillus, Pseudomonas, Delftia, Ochrobactrum, and Rhodococcus [32,33].

The majority of studies on quorum-quenching have focused on the enzymatic degradation of AHL. Studies in this area have identified three main categories of AHL degradation enzymes that correlate with their enzymatic mechanisms [34]. The enzyme categories and their molecular mechanisms are presented in Table 1.

Table 1. AHL enzyme categories and their molecular mechanism.

\begin{tabular}{ll}
\hline \multicolumn{1}{c}{ Enzyme Categories } & \multicolumn{1}{c}{ Mechanism of AHL Degradation } \\
\hline AHL lactonases & $\begin{array}{l}\text { Hydrolysis of the AHL lactone ring to form the corresponding N-acyl } \\
\text { homoserine. This process can also occur spontaneously in the presence } \\
\text { of an alkaline } \mathrm{pH} \text { and can be reversed when the } \mathrm{pH} \text { is acidified }\end{array}$ \\
\hline AHL acylases & $\begin{array}{l}\text { Degradation of the AHL amide bond and generation of the } \\
\text { corresponding free fatty acid and a lactone ring }\end{array}$ \\
\hline AHL oxidoreductases & $\begin{array}{l}\text { Modification (oxidation) and subsequent degradation of signal } \\
\text { QS molecules }\end{array}$ \\
\hline
\end{tabular}

The enzymes and enzyme complexes listed above can degrade AHL and, as a result, prevent pathogenic bacteria from producing virulence factors and forming biofilms, thereby reducing their virulence.

The differences between the mechanisms of the enzymes that degrade AHL's can be seen more clearly in the figure below (Figure 2).

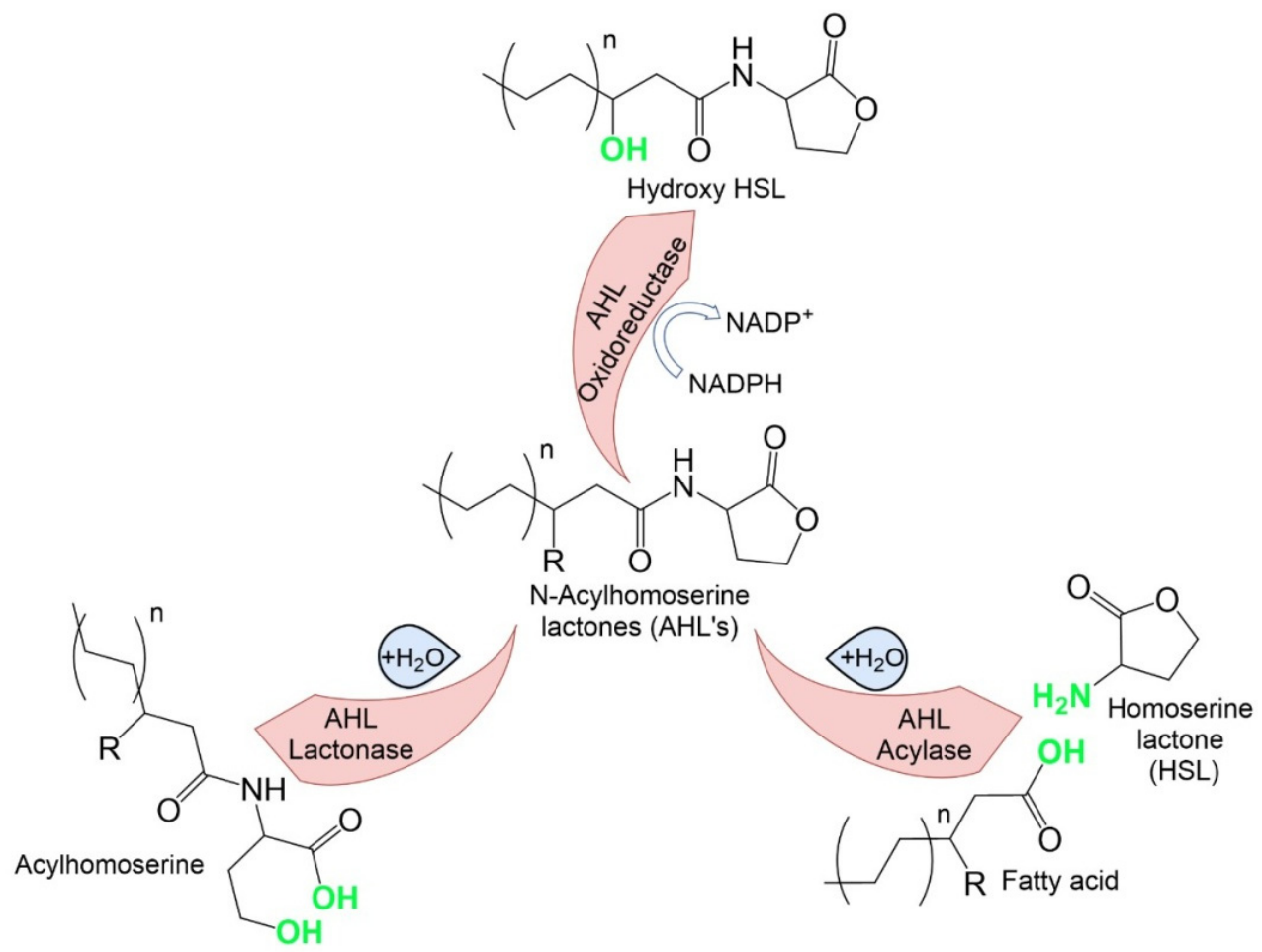

Figure 2. AHL enzymes and their molecular mechanism. 
The first bacteria capable of degrading foreign QS signals were isolated from soil and subsequently identified as members of the genus Bacillus [35]. Spore-forming bacteria of the genus Bacillus have long been known for their high antagonistic potential against a wide range of microorganisms. These bacteria are often referred to as biological control agents and plant growth-promoting bacteria [36,37].

Members of the genus Bacillus have many desirable properties as biocontrol agents, such as ease of cultivation, long-term storage as preparations (due to the ability for spore formation), wide temperature tolerance, etc.

The ability to control the growth of other microorganisms by bacteria of this genus is due to both the production of a wide range of antibacterial and antifungal molecules [38] and the ability to suppress communication inside biofilms and fungal cell groups by quorum-quenching molecules, as will be shown below. At present, many authors have shown that bacilli actively inhibit foreign QS signals and can be isolated from various microbial communities.

For example, Dong et al. [35] showed that B. thuringiensis, B. cereus, and B. mycoides strains isolated from soil and plant samples exhibited a high potential to inactivate AHL. It is known that the listed bacterial species belong to the B. cereus group. Because of this, the subsequent work of these authors focused on the bioinformatic search for AHL-lactonase homologs in bacteria also belonging to this group. The authors' analysis revealed an AHL-lactonase homolog in B. anthracis (gnl/TIGR_1392/banth_2063), in which 89.1\% of the nucleotides are identical to those in the aiiACOT1 coding sequence, suggesting that B. anthracis may contain a similar AHL-inactivating enzyme. However, the role of AHL lactonase in B. anthracis is not completely clear.

Anandan and Vittal (2019) [39] isolated the endophytic Bacillus thuringiensis strain KMCL07 with high lactonase activity against Pseudomonas aeruginosa lactones from plants. Further study of the isolated strain concluded that its high QQ activity was due to the production of lactonase AiiA, which belongs to the metal- $\beta$-lactamase superfamily [39].

QQ in the rhizosphere likely plays a major role in PGPR (plant growth-promoting rhizobacteria) and plant interactions and likely has a significant impact on plant health through the suppression of pathogenic microbiota in the plant rhizosphere.

Although, for the most part, AHLs have more of an indirect negative effect (by increasing pathogen biomass and, consequently, causing more severe forms of the disease). However, various studies have shown that the presence of AHLs in the rhizosphere directly induces various functional and some beneficial responses in various plants [40-42]. This shows the importance of AHL from beneficial bacteria in the rhizosphere for better growth and development of plants, demonstrating the role of QS signals as cross-kingdom messengers. Probably, to prevent the reproduction of a bacterial group that is antagonistic to its species, but at the same time not to suppress harmless ones, bacteria capable of quenching foreign QS signals must have recognition systems that trigger a response to external threats.

For example, the authors of one study demonstrated that B. subtilis induces the expression of the $y t n \mathrm{P}$ gene only in the presence of streptomycin, an antimicrobial agent produced by the Gram-positive bacterium Streptomyces griseus, which would threaten the survival of a Bacillus population. The $y t n \mathrm{P}$ gene encodes a lactonase homologous protein that can inhibit the signaling pathway required for streptomycin production and aerial mycelial development in S. griseus [43].

This behavior serves as a protective strategy against antagonistic bacteria because it allows B. subtilis to inhibit the QS system of harmful microbial communities selectively. Selective inhibition of QS would not occur if B. subtilis triggered $y t n P$ expression in response to the presence of lactone molecules. To ensure that the QQ activity by YtnP acts only in the presence of antibacterial molecules or other stressors that disrupt B. subtilis cell physiology, YtnP is expressed as a cytoplasmic enzyme, just like other quorum-quenching enzymes [43]. Consequently, the release of YtnP into the extracellular space co-occurs with cell lysis, which is a peculiar mechanism for regulating the activity of a QQ system in the rhizospheric coexistence of soil bacilli with other community members. 
In addition to soil and plant-associated bacilli, the production of AHL-degrading enzymes was also found in strains isolated from marine water communities. McBride and Strickland [44], for example, showed that the most active of the sediment strains they isolated was Bacillus pumilus S8-07. This bacterial strain reduced the accumulation of $\mathrm{N}$-acyl homoserine lactones (AHLs) and showed significant inhibition of the production of LasA protease, LasB elastase, caseinase, pyocyanin, pyoverdine, and biofilm formation in P. aeruginosa $\mathrm{PAO1}$, and showed a significant decrease in prodigiosin synthesis, secreted caseinase, hemolytic activity, and biofilm formation in Serratia marcescens [45]. It is also worth noting that the authors of this work were the first to demonstrate that QQ-activity can be caused not by the action of lactonase, as has often been demonstrated in other works, but by the action of an enzyme with acylase activity in bacilli.

In another study, the authors isolated a quorum-quenching Bacillus sp. Strain, designated as QSI-1, from the intestines of healthy fish (Carassius gibelio). QSI-1 was found to inhibit AHL-dependent violacein production in Chromobacterium violaceum, reduce the production of virulence factors such as proteases, hemolysins, and inhibit biofilm formation in Aeromonas hydrophila YJ-1 [46]. The data presented by these authors also allows considering Bacillus representatives as probiotic strains for aquaculture.

Although most studies are focused on quenching QS signals of a lactone nature, data on the ability of Bacillus bacteria to interact with other signaling molecules, including mediators of QS in Gram-positive bacteria, have recently been published. For example, it was shown that $B$. subtilis could inhibit QS in $S$. aureus due to the competitive interaction of the Bacillus synthesized lipopeptide fengicin with AgrC, a receptor for staphylococcal AIP. At the same time, comparative studies in human populations indicate that the effect is not limited to the intestinal microbiome but is systemic: in a rural Thai population, consuming probiotic $B$. subtilis led to the eradication of $S$. aureus in the nasopharynx. This may be related to the anti-biofilm effect achieved by the synthesis of molecules with QQ-activity [47]. Agr-like QS-systems also exist in other pathogenic bacteria, particularly in Clostridium perfringens, which causes necrotizing enteritis in chickens [27]. Recent work has shown that this is also characteristic of the important human pathogen Clostridioides difficile [48]. At the same time, no enzymatic systems that suppress QS in this pathogen have yet been identified. Still, the similarity of the QS system with that in S. aureus allows us to hope for the successful use of probiotic Bacillus strains. The ability of subtilisin A to block QS in the opportunistic actinobacterium Gardnerella vaginalis through interaction with the autoinducer AI-2 has also been shown [49].

In summary, it is worth emphasizing that bacteria of the genus Bacillus, as this chapter shows, are the most promising targets for the study of QQ-systems since they have ubiquitous occurrence and various mechanisms for the enzymatic degradation of QS-signaling Gram-negative bacteria, namely production of AHL-lactonases, and as shown relatively recently, AHL-acylases. The search for strains capable of effectively counteracting the QS systems of Gram-positive bacteria represents a new and very pressing challenge that has yet to be addressed.

\subsubsection{Lactic Acid Bacteria as Quorum-Quenching Agents}

Since ancient times, lactic acid bacteria (LAB) have played an essential role in human life. Many types of lactic acid bacteria are used to create traditional food in different countries. Lactobacilli are an integral part of the normal intestinal microbiota of humans and other animals. Also, lactobacilli, especially Lactobacillus acidophilus, Lactobacillus delbrueckii subsp. lactis (formerly Lactobacillus lactis), Lactiplantibacillus plantarum (formerly Lactobacillus plantarum), are some of the most popular probiotics.

Mainly, when talking about the benefits of lactic acid bacteria, it comes to the fact that they produce lactic acid and other substances (bacteriocins, hydrogen peroxide, diacyls, and others) that inhibit the growth of other bacteria. Lactic acid lowers the $\mathrm{pH}$ of the medium, which is detrimental to the development of putrefactive bacteria. Lactic acid bacteria also often play an immunomodulatory role as symbionts of the gastrointestinal 
tract. For example, lactic acid causes macrophage polarization in the anti-inflammatory M2 phenotype [50].

Lactobacilli have a wide range of properties, in particular, antagonism to other microorganisms. Nonetheless, they are less commonly regarded as QS regulators of pathogens than other Gram-positive bacteria such as bacilli. However, there is evidence showing the potential activity of lactobacilli as QQ agents. As we will discuss further, lactic acid bacteria can potentially affect QS, mediated by acylated homoserine lactones (AHL, HSL) and furanosyl borate diester (also known as autoinducer 2 or AI-2)

A recent review by Gunaratnam S. et al. (2021) [48] describes how some probiotic strains of LAB exhibit inhibitory activity against the QS system and its processes in Gramnegative bacteria. However, it is also possible to add information to the discussion. Today, there is growing evidence concerning the $\mathrm{QQ}$ activity of $\mathrm{LAB}$, though it's still unclear which molecules play a key role.

In 2018, J. Kim et al. [51] showed that the probiotic L. acidophilus 30SC can disrupt biofilm formation in an E. coli O157:H7 strain. In the presence of the cell extract of L. acidophilus 30SC, the level of biofilm formation was significantly lower than that of wild-type E. coli and approached the level of an E. coli O157:H7 luxS isogenic mutant, which is unable to produce AI-2.

It was found that L. acidophilus 30CS can also significantly inhibit the AI-2 activity of E. coli O157:H7. It was discovered using a bioluminescence test based on Vibrio harveyi strain BB170 acting as a positive control of the AI-2 sensor signal [51,52].

In an earlier work by J. Kim et al. (2012) [53], it was shown that some cell extracts of Bifidobacterium spp. have similar activity, although, strictly speaking, bifidobacteria are not LAB. They can also suppress biofilm formation and AI-2 activity in E. coli O157:H7. However, comparing these results with the similar work discussed above makes it clear that L. acidophilus has more significant inhibitory activity and can claim to be a more promising QQ agent.

Interestingly, there is evidence of the ability of various Lactobacillus species to inhibit the activity of various acyl-homoserine lactones. For example, in a study by Kampouris et al. (2018) [54] focused on solving the problem of overgrowth on filtration membranes, it was shown that lactic acid bacteria can inhibit N-Hexanoyl-L-homoserine lactone (6-HSL). These lactic acid bacteria were isolated from activated sludge, identified as L. plantarum, and encapsulated in alginate beads. The maximum results were observed in L. plantarum strain SBR04MA. Within $9 \mathrm{~h}$, this strain degraded all 6-HSL. It also successfully suppressed the biofilm formation of other species from activated sludge and, as a result, suppressed the synthesis of various exogenous polysaccharides that clog the pores of the filter membrane.

It has been shown that L. plantarum CY-1 can act as a QQ agent against Aeromonas sobria, which is a common pathogen in aquaculture [55]. L. plantarum CY-1 is able to synthesize ASH of various lengths: C4, C6, C8 ++, C10 ++, C12 [56]. However, the ratio of "non-classical" carbon lengths to the more common C4- and C6-HSL is small.

In previous work by Ly et al. (2021), it was shown that different strains of L. plantarum degrade HSL, but the type of HSL was not specified. To determine whether the activity was inhibited, a test with Chromobacterium violaceum was used, which releases the violet pigment violacein in response to the presence of HSL. However, at the moment, it is known that entirely different types of HSL can act as inducers for the synthesis of violacein [57]. Nevertheless, a strain was isolated that is capable of degradation of HSL by almost $100 \%$. In this regard, it was shown that the strain inhibits the development of biofilms and affects the synthesis of virulence factors.

Cui T. et al. (2020) [58] showed that Lactobacillus crustorum ZHG 2-1 (re-classified as Companilactobacillus crustorum) isolated from pickled cucumbers has a similar effect on P. aeruginosa. Cell extracts of this strain are capable to destroy two types of HSL: C4 and 3-oxo-C12 dose-dependently $(1 \mathrm{mg} / \mathrm{mL}, 2 \mathrm{mg} / \mathrm{mL}$ and $3 \mathrm{mg} / \mathrm{mL}$ caused degradation of C4-HSL $37.13 \%, 55.36 \%$ and $76.28 \%$, respectively and degradation of 3-oxo-C12-HSL $43.25 \%, 63.71 \%$ and $87.62 \%$, respectively). Inhibition of biofilm formation, reduction of 
swarming and swimming motilities, and inhibition of virulence factors (chitinase and protease) were also observed without affecting bacterial growth.

There is another example of the influence of lactic acid bacteria metabolites on QS in P. aeruginosa. Rana et al. (2020) [59] investigated the effect of lactic acid bacteria's acidic and neutral cell-free supernatants on QS and QS-associated processes. The effect differed both between the types of supernatants and between the methods of their use. For example, the most exciting results were shown by the acidic supernatants of Lactococcus lactis NCDC 309 , which were added to the medium inoculated with pseudomonads only. In this case, effective inhibition of biofilm, AHL, elastase, and lasI and rhiI expression was observed.

Interestingly, neutral supernatants of all studied strains have a controversial effect. On the one hand, these supernatants effectively degraded AHL (5-10 times compared to the control), and on the other hand, they stimulated or did not affect elastase activity. What is especially interesting, is that the neutral supernatants of Lactobacillus fermentum MTCC 5898 (reclassified as Limosilactobacillus fermentum), Lactobacillus rhamnosus MTCC 5897 (reclassified as Lacticaseibacillus rhamnosus), and L. lactis NCDC 309 in different cases showed an increase in the expression of lasI and rhiI in comparison with the control.

To date, no data revealing the mechanisms of QQ by LAB in detail is available. It could be assumed that lactonases are responsible for the destruction of AHL in LAB. According to Rana et al. (2020) [59], the acidic supernatant with $\mathrm{pH} 4.0$ had a more pronounced AHL-degrading activity. However, there is data showing AHL lactonase has the optimal $\mathrm{pH}$ range of 6-8, which corresponds to a more neutral environment $[60,61]$. Interestingly, the molecules themselves are more stable in an acidic environment, and they undergo non-enzymatic lactonolysis at $\mathrm{pH}$ between 5-8 [62]. It should be noted that there is no convincing evidence that lactic acid bacteria, particularly lactobacilli, are capable of producing AHL lactonases. This suggests that, most likely, other molecules that have not yet been identified are involved in the degradation of AHL in LAB.

In addition to the ability of lactobacilli to suppress QS-signaling in Gram-negative bacteria by interacting with various types of AHL, there are many studies devoted to their interaction with QS-signals from Gram-positive bacteria. The most significant number of works is devoted to the suppression of QS in S. aureus. For example, culture supernatants of Lactobacillus reuteri RC-14 (reclassified as Limosilactobacillus reuteri) suppressed the expression of agr genes, and cyclic dipeptides cyclo (L-Phe-L-Pro) and cyclo (L-Tyr-L-Pro) played a crucial role in this inhibition [63]. Yan et al. (2019) [64] showed that biosurfactants produced by L. plantarum and P. acidilactici reduce the expression of the cidA, icaA, dltB, agr $A$, sortase A, and sarA genes associated with biofilm formation in $S$. aureus, as well as reducing the expression of $\mathrm{AI}-2$ in a dose-dependent manner.

Among other Gram-positive pathogenic bacteria, QS in Listeria monocytogenes was inhibited by the metabolites of L. plantarum M.2 and Lactobacillus curvatus B.67 (reclassified as Latilactobacillus curvatus) due to inhibition of agr genes [65]. A similar mechanism has been noted for C. difficile, which has been shown to inhibit AI-2 and the QS (luxS) system upon adding heat-treated supernatant $L$. fermentum Lim2 [66]. These data may indicate the low molecular nature of the metabolites involved in QQ of Gram-positive bacteria in lactobacilli. The information about LAB strains capable of QQ is summarized in Table 2.

The question remains: why do different strains affect certain forms of QS? As can be seen from the discussion and the summary table above, some strains can inhibit different types of AHL, others-AI-2 signaling. In the authors' opinion, this issue is not fully resolved and is not yet clear, because usually only one of the inhibitory pathways is studied: either against AHL or AI-2, as well as against the processes associated with QS in general (biofilm formation, the activity of pathogenic factors, etc.). In addition, the study of AI-2 inhibition comes down to using a biosensor to understand whether there is inhibition or not and how strong it is. However, knowledge about the nature of this inhibition remains exceptionally vague, especially in lactic acid bacteria. 
Table 2. Strains of lactic acid bacteria-QS antagonists.

\begin{tabular}{|c|c|c|c|}
\hline Strain & Mechanism & Against & References \\
\hline L. acidophilus 30SC & AI-2 Inhibition & E. coli O157:H7 & [51] \\
\hline L. plantarum SBR04MA & $\begin{array}{l}\text { N-Hexanoyl-L-homoserine } \\
\text { lactone (6-HSL) inhibition }\end{array}$ & $\begin{array}{l}\text { Microbiota of } \\
\text { activated sludge }\end{array}$ & {$[54]$} \\
\hline L. plantarum CY-1 & $\begin{array}{l}\text { HSL degradation (without } \\
\text { details). }\end{array}$ & A. sobria & [67] \\
\hline C. crustorum ZHG 2-1 & $\begin{array}{l}\text { Dose-dependent degradation } \\
\text { C4- and 3-oxo-C12- HSL }\end{array}$ & P. aeruginosa & [58] \\
\hline $\begin{array}{l}\text { Cell-free acidic } \\
\text { supernatants L. lactis } \\
\text { NCDC } 309, \text { L. rhamnosus } \\
\text { MTCC 5897, L. rhamnosus } \\
\text { MTCC 5857, L. fermentum } \\
\text { MTCC 5898, L. acidophilus } \\
\text { NCDC 15, L. delbrueckii } \\
\text { subsp. lactis, L. plantarum } \\
\text { NCDC } 372 \text {, }\end{array}$ & $\begin{array}{l}\text { Inhibition of biofilm formation, } \\
\text { elastase, and expression of lasI } \\
\text { and rhlI }\end{array}$ & P. aeruginosa & [59] \\
\hline $\begin{array}{l}\text { Cell-free neutral } \\
\text { supernatants of some of the } \\
\text { strains described above }\end{array}$ & $\begin{array}{l}\text { Depending on the strain, both } \\
\text { the lack of effect and the } \\
\text { stimulation of some QS processes } \\
\text { (an increase in the expression } \\
\text { level of QS-related genes, } \\
\text { elastase activity) were observed }\end{array}$ & P. aeruginosa & [59] \\
\hline L. reuteri $\mathrm{RC}-14$ & $\begin{array}{l}\text { Inhibition of agr gene expression } \\
\text { by cyclic dipeptides } \\
\text { cyclo(L-Phe-L-Pro) and } \\
\text { cyclo(L-Tyr-L-Pro) }\end{array}$ & S. aureus & [55] \\
\hline L. plantarum, P. acidilactici & $\begin{array}{l}\text { Reduce expression of genes } \\
\operatorname{cid} A, i c a A, d l t B, \operatorname{agr} A \text {, sortase } \mathrm{A}, \\
\text { and } \operatorname{sar} A \text { involved in } \\
\text { biofilm formation }\end{array}$ & S. aureus & {$[65]$} \\
\hline $\begin{array}{l}\text { L. plantarum M.2, } \\
\text { L. curvatus B. } 67\end{array}$ & Inhibition of $a g r$ genes & $\begin{array}{l}\text { Listeria } \\
\text { monocytogenes }\end{array}$ & {$[65]$} \\
\hline $\begin{array}{l}\text { Heat-treated supernatant } \\
\text { L. fermentum Lim } 2\end{array}$ & Inhibition of $a g r$ genes & C. difficile & {$[66]$} \\
\hline
\end{tabular}

\subsection{Actinobacteria}

Actinobacteria are a widespread type of microorganisms showing a broad phenotypic diversity, making them indispensable for the biotechnology industry. They play an essential role in the soil ecosystem due to their ability to decompose organic matter. In addition, actinobacteria are widely distributed in the rhizosphere and produce a wide range of biologically active metabolites that affect plant development [68]. Their ability to synthesize a wide range of secondary metabolites such as antibiotics and fungicides $[69,70]$ and their ubiquity make them ideal biological control agents. Actinobacteria are often considered to be regulators of QS.

Actinobacteria are a promising biocontrol agent for reducing soft rot and blackleg caused by Pectobacterium carotovorum subsp. carotovorum [71]. In a study of 40 marine actinobacteria isolates, 10 had QQ activity. These isolates were able to inhibit biofilm formation in P. aeruginosa ATCC 27853, S. typhimurium, V. cholerae, B. cereus ATCC 14579, S. aureus ATCC 29213, and E. faecalis ATCC 33186 [72].

In a different study 8 Actinomycetes isolates had the ability to inhibit biofilm formation in B. cereus, B. subtilis, and S. putrefaciens, presumably due to their ability as anti-QS agents. QQ activity was determined by treating $C$. violaceum with isolate extracts and measuring the degree of inhibition of violacein production [73]. Also, screening of soil and endophytic actinomycetes for QQ activity was attempted, and it was shown that $51.5 \%$ of 
the strains studied possessed this activity, with $36.9 \%$ more such activity occurring among endophytic strains [74].

Several genera of this phylum showed the ability to inhibit QS. For example, Arthrobacter sp. demonstrated the ability to degrade 3-oxo-C6-HSL and some other N-acyl-homoserine lactones with the help of AhlD lactonase. A co-culture experiment demonstrated the ability to reduce the virulence of the soft rot pathogen P. carotovorum N98 [75].

Microbacterium testaceum demonstrated the ability to inhibit exoenzyme release by the potato soft rot pathogen P. carotovorum subsp. Carotovorum, which is induced by AHLmediated QS. Microbacterium testaceum can degrade AHL using AiiM, an AHL lactonase from the Fold family of hydrolases. M. testaceum is an endophytic bacterium; given its antipathogenic activity, it can be used as a biological control agent [76].

The ability of Micromonospora sp. TAV14 to inhibit P. aeruginosa PAO1 swarming by disrupting the rhl-regulated rhamnolipid responsible for swarming has also been shown [77].

It has also been reported that Streptomyces sp. can synthesize AHL acylase, which explains their ability to inhibit pathogen virulence factors. The ahlM gene encodes its AHL acylase, showing some similarity to the AHL acylases of strains Ralstonia XJ12B (AiiD) and P. aeruginosa PAO1 (PvdQ) and the cyclic lipopeptide acylases of strains Streptomyces sp. FERM BP-5809 and Actinoplanes utahensis [78]. Based on these findings, we can conclude that AhlM may have the ability to degrade not only AHL but also cyclic lipopeptides. In P. aeruginosa, elastase, LasA-, and casein protease activities are reduced under the influence of AhlM [79]. In another study, Streptomyces sp. NIO 10068 and Streptomyces sp. NIO 10058 extracts containing cinnamic acid as the main compound was found to inhibit P. aeruginosa ATCC 27853 [80]. As in the case of Micromonospora sp, this activity is due to its effect on rhl-regulated rhamnolipid synthesis [77].

Rhodococcus erythropolis is of particular interest because all 3 types of AHL degradation enzymes, AHL lactonase, acylase, and oxidoreductase are produced, which is very rare. Genomic studies show that besides R. erythropolis, only three other organisms possess AHL-lactonase and AHL-acylase activities together: Deinococcus radiodurans, Hyphomonas neptunium, and Photorhabdus luminescens subsp. Laumondii [81]. In addition, the AHL lactonase of R. erythropolis belongs to a unique class, unlike the common AiiA-type lactonases. Its lactonase QsdA (Quorum-sensing signal degradation) belongs to phosphotriesterases and is capable of degrading a wide range of AHL [82,83]. A wide range of AHL signaling molecules is degraded by AHL acylase and AHL oxidoreductase for which specific genes have not yet been identified [84]. Another interesting point is that according to C. Barbey [85], QQ activity in R. erythropolis is induced by the presence of QS molecules, namely AHL, in the environment. QS activity is regulated by the qsd (QS signal degradation) operon, which includes genes encoding lactonase QsdA and fatty acyl-CoA ligase QsdC, which are involved in AHL degradation by affecting the lactone ring and acyl chain fragments. The operon is regulated by the QsdR repressor, a member of the TetR-like receptor family. Using interacting approaches and a transcriptional fusion strategy, they elucidated the mechanism of repressor removal. The homoserine lactone ring binds to the effector domain of QsdR, thereby preventing QsdR from binding to the qsd promoter region [86].

The information about Actinobacteria strains capable of QQ is summarized in Table 3.

Table 3. Strains of Actinobacteria-QS antagonists.

\begin{tabular}{|c|c|c|c|}
\hline Strain & Mechanism & Against & References \\
\hline Rhodococcus pyridinivorans & 3-oxo-C6- N-acyl homoserine & Pectobacterium & \\
\hline AI 4 & lactone degradation & carotovorum & [/1] \\
\hline Glutamicibacter nicotianae & 3-oxo-C6- N-acyl homoserine & Pectobacterium & [71] \\
\hline $\mathrm{AI} 5 \mathrm{a}$ & lactone degradation & carotovorum & [/1] \\
\hline Arthrobacter sp. IBN110 & $\begin{array}{l}\text { 3-oxo-C6- N-acyl homoserine } \\
\text { lactone degradation }\end{array}$ & $\begin{array}{l}\text { Pectobacterium } \\
\text { carotovorum } \mathrm{N} 98\end{array}$ & [79] \\
\hline $\begin{array}{l}\text { Microbacterium testaceum } \\
\text { StLB037 }\end{array}$ & C10-HSL degradation & $\begin{array}{l}\text { Pectobacterium } \\
\text { carotovorum }\end{array}$ & [76] \\
\hline Micromonospora sp. TAV14 & Disruption of rhl-regulated QS & P. aeruginosa PAO1 & [77] \\
\hline
\end{tabular}


Table 3. Cont.

\begin{tabular}{|c|c|c|c|}
\hline Strain & Mechanism & Against & References \\
\hline $\begin{array}{l}\text { Streptomyces sp. NIO } 10068, \\
\text { Streptomyces sp. NIO } 10058\end{array}$ & Disruption of rhl-regulated QS & $\begin{array}{l}\text { P. aeruginosa } \\
\text { ATCC } 27853\end{array}$ & [80] \\
\hline Rhodococcus erythropolis R138 & $\begin{array}{l}3 \text { types of AHL degradation } \\
\text { enzymes, AHL lactonase, } \\
\text { acylase, and oxidoreductase }\end{array}$ & $\begin{array}{l}\text { Pectobacterium } \\
\text { atrosepticum CFBP } 6276\end{array}$ & {$[81,82]$} \\
\hline
\end{tabular}

Based on the above, we can say that actinobacteria are promising subjects for the study of QQ. Also, this type has several bacteria shown to be promising agents for controlling Gram-negative plant pathogens whose pathogenicity is due to QS signals.

\section{The Evolutionary and Ecological Role of QQ}

Quorum-quenching, being an important process in the vital activity of microorganisms, has considerable ecological and evolutionary significance. Indeed, if we consider that microorganisms are ubiquitous, and in the course of hundreds of millions of years of evolution, have competed with each other for certain eco-niches, we can expect the influence of QS systems and their suppression on the evolution of some groups of bacteria.

One of the essential aspects of this effect is the reduction of the protection of the population exposed to $Q Q$ from bacteriophage infection. It has been proven that QS plays a role in increasing protection against phages. So, on the one hand, given the prevalence of bacteria in the form of a biofilm, it would be logical to assume that bacteriophages have "learned" to effectively infect bacteria in biofilms. Indeed, phages can produce enzymes that destroy the extracellular matrix and, in general, cope well with a biofilm barrier [86].

However, it has also been shown that a biofilm can still prevent or slow down phage infection in the population, hindering the penetration of phages. Microorganisms take protective measures in conditions of high population density and, accordingly, high risk of infection [52]. It is known that the interaction of bacteriophages with bacterial biofilms proceeds along different paths and depends on many factors (phage size, its specificity, the presence of enzymes that destroy the biofilm in the phage, the composition of the biofilm itself, its density) [87].

QQ has an overwhelming effect on the molecular signals responsible for countering phage infection. For example, the QQ mechanism suppresses biofilm formation [5]. Suppression of biofilm formation under the action of QQ enzymes has been actively studied [88]. In this way, some bacteria are capable of weakening the anti-phage defense of their competitors. After eliminating competitors by phages, these bacteria can occupy their niches (the high specificity of bacteriophages allows minimizing the negative consequences for a competitor using the $\mathrm{QQ}$ mechanism, with negative consequences for a bacterium with a suppressed QS system and, consequently, weakened protection against phages).

Thus, QQ influences both the ecology of phages and the evolution of host bacteria. It is well known that bacteriophages play a crucial role in horizontal gene transfer between microorganisms [89]. In the context of microbial ecology and the relationship between groups of Gram-positive and Gram-negative bacteria, many examples of QS suppression in Gram-negative bacteria are known [90]. In this case, suppression of biofilm formation in Gram-negative bacteria allows slower-growing Gram-positive bacteria to successfully colonize microniches in environments such as soil and the rhizosphere.

Even though QQ is often used in the competition of microorganisms, this effect also has the role of cleansing the microenvironment of bacterial signaling molecules (the bacterium itself, which produced the QS signal, suppresses, or destroys the signal). It is necessary to reduce the quantity and concentration of information signals around the bacterium - after all, a large number of old signals can interfere with the perception of new, more important ones. Therefore, the ecological effect of $Q Q$ as a purification from "superfluous" information around is no less important than the effect of QQ in competition [2]. 
Considering the evolutionary aspect, we should mention the phylogenetic relationships of various genes (proteins) responsible for QQ and QS. Such relationships were explored in the study of Kalia V.C. et al. [91]. Their study examined the phylogeny of AHL acylases (cleavage of the acyl chain) and AHL lactonases (hydrolysis of the lactone ring). In particular, it was found that AHL-lactonase is present in large quantities among representatives of Firmicutes and $\alpha$-proteobacteria (in general, it provides these enzymes, distributed between groups: Actinobacteria, Acidobacteria, Bacteroidetes, Chloroflexi, Deinococcus-Thermus, Firmicutes, $\alpha$-Proteobacteria, $\beta$-Proteobacteria, $\gamma$-Proteobacteria, $\delta$-Proteobacteria, Euryarchaeota, Crenarchaeota, Sphingo-bacteria, Spirochaetales, Nitrospirales and Planctomycetes).

It was also shown that the distribution of sequences for AHL-acylase (the frequency of occurrence, for example, in many proteobacteria) was more limited in comparison with the distribution of sequences of AHL-lactonase.

On the other hand, cyanobacteria were found to possess only AHL acylases, while Acidobacteria, Sphingobacteria, Spirochaetales, Nitrospirales, and Planctomycetes possess only AHL lactonase. In the course of studying the sequences encoding these enzymes, regions were found that are specific for specific taxonomic classes, as well as regions that are universal for different taxonomic classes. In summation, there is an unevenness in the distribution of genes of lactonases and acylases between strains of different taxonomic groups of microorganisms, and in the sequences themselves, there are areas common to large taxa and variables.

As can be seen, the evolution of the strains was accompanied by a parallel evolution of the QQ genes, during which the variable regions of the lactonase and acylase genes changed in the zone of the variable regions [91].

It is also possible to trace the evolutionary relationship between the genes of QS synthases. These genes are similar in phylogenetically close strains of microorganisms. For example, the study by Goh et al. [92] carried out a phylogenetic analysis using the example of Citrobacter amalonaticus L8A QS synthases.

The QQ effect is used not only in interactions between microorganisms but also during cross-kingdom interactions: plants can also suppress the QS signals of bacteria. For example, they can effectively suppress information signals from plant pathogens and thus protect themselves from pests (many plant extracts have been tested to suppress QS in bacteria and have shown a QQ effect). However, it cannot be said unequivocally that the suppression of QS bacteria by plants has only a positive effect-in some cases, bacterial QS signals are aimed at triggering the expression of bacterial genes that promote plant growth and protection (for example, the production of antibiotics and antimycotics to protect the plant from the pathogen). In this way, by suppressing QS signals aimed at maintaining a healthy plant life, it is possible for the plant to indirectly cause harm to itself [2].

Another important aspect of the effect of QQ on the metabolism of microorganisms and their vital activity, in general, is the effect on the production of extracellular enzymes by bacteria. For example, the suppression of QS signals may decrease the production of intracellular enzymes, which may have significant consequences for microbiological processes in nature involving extracellular enzymes of microorganisms (such as processing organic matter in the soil et cetera). Therefore, QQ processes can affect microbial communities and the whole environment [44].

Although QQ is less studied, its influence has already been considered, for example, in studies of sewage treatment in plant communities. Furthermore, it was shown that the QQ effect is less variable during the operation of the treatment facilities, while the QS effect gradually decreased. This suggests the possibility of a greatly underestimated long-term role of $Q Q$, which may have a permanent impact on microbial communities [93].

Thus, the occurrence of $Q Q$ is determined by the continuous evolution of microorganisms. The need to exchange information in complex communities arose with the advent of the communities themselves. Coordination of activities was needed, and the language of chemical formulas was quite suitable for bacterial "communication." As a need to clear the microenvironment of unnecessary signals, $Q Q$ is likely to have appeared along with 
the emergence of QS. The evolution of the QS and QQ systems goes on in parallel, and new types of informational chemical signals continue to arise during this process. In summation, we can trace the importance and breadth of the influence of QQ mechanisms that have recently begun to be actively studied. The environmental impact of the QQ effect is mediated by the importance of QS, which it directly affects, and the evolutionary context of QQ has a long history throughout the evolution of microorganisms.

\section{Prospects for Use: The Fight against Pathogens, the Improvement of Probiotics' Efficiency, and Plant Protection}

The potential application of microorganisms capable of effectively controlling the QS of pathogens is straightforward. Many studies are aimed at finding effective QS antagonist strains for practical applications in medicine, veterinary medicine, and agriculture. There are two major areas of application of Gram-positive microorganisms to combat biofilm formation.

\subsection{The Use of Microorganisms and Substances with QQ Activity to Protect Animals}

Since QS leads to the expression of many virulence factors of pathogenic bacteria, the idea of inhibiting QS to treat bacterial infections has been in the air since the discovery of QQ. Some successes have been achieved in this field using compounds with QQ-activity, especially as an integral part of complex antibiotic therapy [21,94].

There have also been several successful trials of drugs based on AiiA, the bacillary lactonase. The whole area of QQ studies began with AiiA. In 2012, Yanan Cao et al. [95] applied bacillary lactonase AiiA by adding it to zebrafish feed, and this resulted in a significant reduction in Aeromonas hydrophila infection. Also, the combination of AiiA with QSI molecules made it possible to completely block the LasR/I and RhlR/I QS pathways in Pseudomonas aeruginosa [96]. Bacillary QQ enzymes will be discussed in more detail in the subsection on the use of Gram-positive probiotic bacteria with QQ properties.

The unexpected success of the use of QQ in the context of health care was its use to prevent overgrowth on water filters since the formation of biofilms on their surface reduces their functionality, can cause their occlusion, and lead to deterioration in the quality of pot le water. Numerous works show the effectiveness of the QQ strategy to prevent the clogging of water filters, which finds its application in industry and medicine, since the formation of biofilms on medical equipment is also a widespread problem [52,54,97]

However, it should be understood that the use of compounds with QQ activity as biocontrol agents is considered more advantageous compared to antibiotics in the context of resistance because QQ molecules do not directly kill bacteria and do not contribute to the selection of resistant forms.

Microorganisms that can implement QQ-strategies can be used as potential quenchers of QS-regulated functions in pathogenic bacteria, and they can be used as an environmentally friendly alternative to antibiotics and various fungicides in agriculture and aquaculture [98]. Antibiotic therapy exerts selective pressure on pathogens leading to the survival of resistant forms. This process is widespread due to the frequent use or overuse of antibiotics in husbandry [99] and has been shown to be accelerated in polluted soils and sediments [100].

A specific feature of the QQ strategy is that it weakens the production of virulence factors and, consequently, contributes to the destruction of a biofilm, but does not destroy the pathogen cells themselves, in contrast to the same exposure to antibacterial agents [101]. Therefore, the use of QQ probiotics may be beneficial.

It should be noted, however, that there are more and more reports that the development of resistance to QS inhibitors is still possible, and we need to use them with considerable caution [102].

According to the $\mathrm{WHO}$, probiotics are "live microorganisms which when administered in adequate amounts confer a health benefit to the host" [103]. Among other things, they can be used as an alternative to antibiotics, since their antagonistic action against pathogens 
is multifaceted and involves many mechanisms, which excludes the rapid development of resistance by microorganisms [104]. In this light, the use of probiotics with QQ activity is of great interest, as evidenced by the many works published on this topic in the last 10 years.

Since the first enzyme with QQ activity, AiiA, was found in representatives of the Bacillus genus, the greatest success in the practical application of $Q Q$ was achieved with bacilli and other Gram-positive microorganisms [105].

For example, it has been shown that B. subtilis KATMIRA1933 produces the lantibiotic subtilisin, which significantly suppresses the formation of biofilms by the Gram-positive pathogens Gardnerella vaginalis and Listeria monocytogenes. The activity against QS of the Gram-negative bacteria was assessed using the reporter strain C. violaceum: the level of suppression of biofilm formation was comparable to that for Gram-positive bacteria. In the same study, the authors found that subtilosin reduces the production of QS molecule AI-2 in Gram-positive pathogens; however, the exact mechanism of this effect remains to be elucidated [49].

The probiotic strain Bacillus sp. QSI-1 is used to control infections in farmed fish. The study of the antagonistic properties of this strain against the pathogen A. hydrophila YJ-1, carried out by Zhou et al. (2019) [106], showed that co-cultivation of QSI-1 with this microorganism causes a significant decrease in the production of its virulence factors. The authors associate this result with the disruption of QS pathways of A. hydrophila $[89,106,107]$.

It is also reported that Bacillus licheniformis T-1 exhibits probiotic and QQ properties both in vitro and in vivo. Next-generation sequencing data suggest that this strain contains the $y \operatorname{tn} \mathrm{P}$ gene encoding acyl-homoserine lactone metallo- $\beta$-lactamase, a potential quorum-quencher. QQ activity is confirmed in studies with the reporter strain $C$. violaceum ATCC12472. In addition, with intraperitoneal administration of T-1 to zebrafish infected with $A$. hydrophila cb15, the pathogenicity of this microorganism was significantly reduced, and the relative survival rate of fish reached $70 \%$ [108].

Ghanei-Motlagh et al. (2019) [109] isolated 10 bacterial species from the intestines of barramundi capable of degrading both short-chain and long-chain AHLs associated with common fish pathogens-V. harveyi and V. alginolyticus. Moreover, the researchers tested the probiotic potential of the isolated species in vitro and concluded that at least 2 of the tested strains (B. thuringiensis QQ1 and B. cereus QQ2) meet the criteria for probiotic bacilli such as spore formation, exoenzymes secretion, low $\mathrm{pH}$ tolerance, the ability to adhere to the mucosa, and safety for fish. The same authors determined that $B$. thuringiensis QQ1 and $B$. cereus $\mathrm{QQ} 2$ can significantly reduce the production of $V$. alginolyticus virulence factors (amylase, gelatinase, and protease), as well as inhibit its ability to form biofilms. Also, both probiotics increased Asian seabass survival during V. alginolyticus infection [110].

In addition to the spore-forming probiotics discussed above, some progress has been made in the use of probiotic lactobacilli. Lactobacillus brevis 3M004 (reclassified as Levilactobacillus brevis) is capable of cleaving acyl-homoserine lactones, but its therapeutic potential needs further verification [111]. L. plantarum PA100 is able to inhibit the production of AHL, elastase, and biofilm formation in P. aeruginosa, which is resistant to several antibiotics [112]. Strains L. casei ATCC 393, L. reuteri ATCC 23272, L. plantarum ATCC 14917, and L. salivarius ATCC 11741 demonstrated an inhibitory effect on biofilm formation and gene expression of the QS system (vicR and comD) in Streptococcus mutans, however, the exact mechanisms of this effect are still unknown [113]. Lactobacillus reuteri RC-14, a vaginal isolate, when co-cultured with Staphylococcus aureus MN8, inhibited transcription from the promoters of the agr QS genes (Ptst, P2, and P3). This led to the repression of the synthesis of virulence factors, including exotoxin toxic shock syndrome toxin-1 (TSST-1). This effect on expression was associated with the signal peptides cyclo (L-Phe-L-Pro) and cyclo (L-Tyr-L-Pro) [55].

In addition to all of the above, there are sporadic reports on the use of probiotic enterococci. For example, Enterococcus faecium QQ12 has shown effective degradation of $\mathrm{N}-\mathrm{AHL}$ produced by the pathogen Aeromonas hydrophila, demonstrating the potential of E. faecium as a QQ strain [114]. 
Thus, we see that the potential for developing probiotics with QQ activity is truly enormous, and the sources of new probiotic strains for further selection and use can vary widely.

\subsection{Symbiotic and Mutualistic Microorganisms Capable of Protecting Plants from Pathogens, Exhibiting QQ Properties}

Plants and bacteria have a long history of coevolution, and their ecological relationships range from symbiosis and even mutualism to parasitism. The situation is especially difficult in the rhizosphere, where the networks of interactions are truly immense. In this regard, the issue of using microorganisms to combat plant parasites is quite acute. Since many plant pathogens are capable of forming biofilms, and the use of compounds active against a wide range of microorganisms can damage beneficial bacteria in the rhizosphere, the use of drugs with QQ activity seems to be a logical solution [115].

Dong et al. (2000) [116] were the first to try to use QQ for plant protection. They modified the plant pathogen P. carotovorum with the aiiA lactonase gene isolated from Bacillus sp. 240B1. As a result of this intervention, the secretion of QS autoinducers and other virulence factors was significantly reduced, and the pathogenicity on potato, eggplant, Chinese cabbage, carrot, celery, cauliflower, and tobacco was weakened. In 2001, the same authors transformed tobacco and potatoes with the aiiA gene. The transformed plants showed significant resistance to P. carotovorum [94]. Similar studies with aiiA and other lactonase genes were subsequently carried out by other authors $[117,118]$.

Gram-positive microorganisms are also used directly to combat phytopathogens through QQ. Yi-Hu Dong et al. (2004) [119] tested B. thuringiensis for the prevention of potato soft rot caused by P. carotovorum. It was shown that bacilli do not directly affect the growth of the bacteria, but inhibit the synthesis and accumulation of AHL, which leads to a substantial decrease in the number of infection cases. Also, Bacillus cereus Si-Ps1, an endophyte isolated from the leaves of Citrus sinensis and C. sinensis var. Thomson's, according to a study by Akbari Kiarood et al. (2020) [110], produces an analog of lactonase aii $A$, thereby inhibiting biofilm formation in the bacterium Pseudomonas syringae pv. syringae (Pss) B728a. Since Si-Ps1 is an endophyte, its use for plant protection presents no complications.

Proof of the prospects of $Q Q$ for plant protection is seen in modern screening studies, the authors of which are looking for strains with QQ-activity in the rhizosphere of different plants. For example, Fatemeh Alinejad et al. (2020) [120] isolated several soil microorganisms, including Bacillus pumilus, capable of degrading acyl-homoserine lactone while reducing soft rot in potato tubers by $98 \%$ compared to controls.

However, it should be understood that intervention into the complex environmental relations in the rhizosphere often comes at a cost, and sometimes we may not precisely get the effect we expect since QS systems are not only used by pathogens. Noteworthy in this context is the Bacillus cereus strain U92, which was isolated from the rhizosphere of tomato. It has shown both in vitro high efficiency in degradation of a broad spectrum of AHL and in vivo reduction in the incidence of soft rot on potato tubers and crown gall on tomato roots. On the other hand, this led to a $75 \%$ drop in QS-dependent pyocyanin synthesis by $P$. aeruginosa, a plant growth-promoting bacterium [121]. This again emphasizes that any intervention in complex microbial communities, even more so in cross-kingdom interactions, must be carried out with great care.

\section{Conclusions}

Quorum-quenching activity has been forged by evolution as an effective mechanism of interspecies antagonism. Many pathways underlying pathogenicity and resistance to antimicrobial agents are QS-mediated, thus, the use of QQ is a promising way to fight against pathogenic bacteria. Further studies can lead to the development of new pharmaceuticals with a targeted mode of action. 
The main mechanisms that Gram-positive bacteria use to inhibit QS are inhibition or degradation of autoinducers. Representatives of the Bacillus genus use AHL lactonases, AHL acylases, AHL oxidases, and reductases to degrade AHL; lactic acid bacteria also degrade signaling molecules but are also able to influence the expression of genes involved in QS. Actinobacteria produce lactonases, AHL acylases, oxidoreductases, and also cyclic lipopeptide acylases, which allow them to disrupt lipopeptide signaling.

The QQ-based interactions between different groups of bacteria can also provide new insights into the mechanisms of probiotic activity since most probiotics are gram-positive bacteria.

The studies of QQ in Gram-positive bacteria can improve our understanding of microbial ecosystems functioning in all types of environments-from soils and sediments to the intestinal microbiome. The impairing of QS signals by Gram-positive bacteria can help them to compete for these microenvironments with more rapidly growing Gramnegative species. Its ecological significance can be put in line with complex pathways of secondary metabolites and antibiotic production in Actinobacteria. The growing body of evidence demonstrating the existence of QQ in lactobacilli and bifidobacteria can lead to an assumption that the prevalence of these groups of microorganisms in the intestine is at least partly due to the QQ-mediated competition with Gram-negative species. Further studies are needed to evaluate the role of QQ in the regulation of bacterial communities in various environments.

Author Contributions: Conceptualization, E.V.P. and A.V.G.; writing-original draft preparation, N.G.V., M.P.K., V.N.S., A.A.B., A.G.R., Y.A.B., E.V.P. and A.V.G.; writing-review and editing, M.L.C., E.V.P. and A.V.G.; visualization, V.N.S. and N.G.V.; supervision, V.A.C. All authors have read and agreed to the published version of the manuscript.

Funding: This work was funded by the Ministry of Science and Higher Education of the Russian Federation within the framework of the state task in the field of scientific activity (Southern Federal University, no. 0852-2020-0029). V.A. Chistyakov and M.L. Chikindas acknowledge the support of the Government of the Russian Federation (contract No. 075-15-2019-1880).

Institutional Review Board Statement: Not applicable.

Informed Consent Statement: Not applicable.

Data Availability Statement: Not applicable.

Conflicts of Interest: The authors declare no conflict of interest.

\section{References}

1. Turovskiy, Y.; Kashtanov, D.; Paskhover, B.; Chikindas, M.L. Quorum Sensing: Fact, Fiction, and Everything in Between. In Advances in Applied Microbiology; Elsevier: Amsterdam, The Netherlands, 2007; Volume 62, pp. 191-234. [CrossRef]

2. Grandclément, C.; Tannières, M.; Moréra, S.; Dessaux, Y.; Faure, D. Quorum Quenching: Role in Nature and Applied Developments. FEMS Microbiol. Rev. 2016, 40, 86-116. [CrossRef]

3. Moradi, F.; Hadi, N. Quorum-Quenching Activity of Some Iranian Medicinal Plants. New Microbes New Infect. 2021, $42,100882$. [CrossRef] [PubMed]

4. Weiland-Bräuer, N. Friends or Foes-Microbial Interactions in Nature. Biology 2021, 10, 496. [CrossRef] [PubMed]

5. Paluch, E.; Rewak-Soroczyńska, J.; Jędrusik, I.; Mazurkiewicz, E.; Jermakow, K. Prevention of Biofilm Formation by Quorum Quenching. Appl. Microbiol. Biotechnol. 2020, 104, 1871-1881. [CrossRef] [PubMed]

6. Haque, S.; Yadav, D.K.; Bisht, S.C.; Yadav, N.; Singh, V.; Dubey, K.K.; Jawed, A.; Wahid, M.; Dar, S.A. Quorum Sensing Pathways in Gram-Positive and-Negative Bacteria: Potential of Their Interruption in Abating Drug Resistance. J. Chemother. 2019, 31, 161-187. [CrossRef] [PubMed]

7. Tong, S.Y.C.; Davis, J.S.; Eichenberger, E.; Holland, T.L.; Fowler, V.G. Staphylococcus aureus Infections: Epidemiology, Pathophysiology, Clinical Manifestations, and Management. Clin. Microbiol. Rev. 2015, 28, 603-661. [CrossRef] [PubMed]

8. Deep, A.; Chaudhary, U.; Gupta, V. Quorum Sensing and Bacterial Pathogenicity: From Molecules to Disease. J. Lab. Physicians 2011, 3, 004-011. [CrossRef]

9. Saxena, P.; Joshi, Y.; Rawat, K.; Bisht, R. Biofilms: Architecture, Resistance, Quorum Sensing and Control Mechanisms. Indian J. Microbiol. 2019, 59, 3-12. [CrossRef]

10. Flavier, A.B.; Clough, S.J.; Schell, M.A.; Denny, T.P. Identification of 3-hydroxypalmitic acid methyl ester as a novel autoregulator controlling virulence in Ralstonia solanacearum. Mol. Microbiol. 1997, 26, 251-259. [CrossRef] 
11. Barber, C.E.; Tang, J.L.; Feng, J.X.; Pan, M.Q.; Wilson, T.J.G.; Slater, H.; Dow, J.M.; Williams, P.; Daniels, M.J. A Novel Regulatory System Required for Pathogenicity of Xanthomonas campestris Is Mediated by a Small Diffusible Signal Molecule. Mol. Microbiol. 1997, 24, 555-566. [CrossRef]

12. Gallagher, L.A.; McKnight, S.L.; Kuznetsova, M.S.; Pesci, E.C.; Manoil, C. Functions Required for Extracellular Quinolone Signaling by Pseudomonas aeruginosa. J. Bacteriol. Res. 2002, 184, 6472-6480. [CrossRef] [PubMed]

13. Pascale, G.; Sauriol, F.; Benhamou, N.; Bélanger, R.R.; Paulitz, T.C. Novel Butyrolactones with Antifungal Activity Produced by Pseudomonas aureofaciens Strain 63-28. J. Antibiot. 1997, 50, 742-749. [CrossRef] [PubMed]

14. Passador, L.; Cook, J.M.; Gambello, M.J.; Rust, L.; Iglewski, B.H. Expression of Pseudomonas aeruginosa Virulence Genes Requires Cell-to-Cell Communication. Science 1993, 260, 1127-1130. [CrossRef] [PubMed]

15. Ledgham, F.; Ventre, I.; Soscia, C.; Foglino, M.; Sturgis, J.N.; Lazdunski, A. Interactions of the Quorum Sensing Regulator QscR: Interaction with Itself and the Other Regulators of Pseudomonas aeruginosa LasR and RhlR: Interactions of QscR. Mol. Microbiol. 2003, 48, 199-210. [CrossRef] [PubMed]

16. Tang, H.B.; DiMango, E.; Bryan, R.; Gambello, M.; Iglewski, B.H.; Goldberg, J.B.; Prince, A. Contribution of Specific Pseudomonas aeruginosa Virulence Factors to Pathogenesis of Pneumonia in a Neonatal Mouse Model of Infection. Infect. Immun. 1996, 64, 37-43. [CrossRef] [PubMed]

17. Walters, M.; Sperandio, V. Quorum Sensing in Escherichia coli and Salmonella. Int. J. Med. Microbiol. 2006, 296, 125-131. [CrossRef]

18. Zheng, F.; Ji, H.; Cao, M.; Wang, C.; Feng, Y.; Li, M.; Pan, X.; Wang, J.; Qin, Y.; Hu, F. Contribution of the Rgg Transcription Regulator to Metabolism and Virulence of Streptococcus Suis Serotype 2. Infect. Immun. 2011, 79, 1319-1328. [CrossRef]

19. Rutherford, S.T.; Bassler, B.L. Bacterial Quorum Sensing: Its Role in Virulence and Possibilities for Its Control. Cold Spring Harb. Perspect. Med. 2012, 2, 1. [CrossRef]

20. Kirchdoerfer, R.N.; Garner, A.L.; Flack, C.E.; Mee, J.M.; Horswill, A.R.; Janda, K.D.; Kaufmann, G.F.; Wilson, I.A. Structural Basis for Ligand Recognition and Discrimination of a Quorum-Quenching Antibody. J. Biol. Chem. 2011, 286, 17351-17358. [CrossRef]

21. Kutty, S.K.; Barraud, N.; Pham, A.; Iskander, G.; Rice, S.A.; Black, D.S.; Kumar, N. Design, Synthesis, and Evaluation of Fimbrolide-Nitric Oxide Donor Hybrids as Antimicrobial Agents. J. Med. Chem. 2013, 56, 9517-9529. [CrossRef]

22. Donelli, G. (Ed.) Advances in Experimental Medicine and Biology; Springer International Publishing: Cham, Switzerland, 2016; Volume 901. [CrossRef]

23. Slamti, L.; Lereclus, D. Specificity and Polymorphism of the PlcR-PapR Quorum-Sensing System in the Bacillus Cereus Group. J. Bacteriol. 2005, 187, 1182-1187. [CrossRef]

24. Banerjee, G.; Ray, A.K. Quorum-Sensing Network-Associated Gene Regulation in Gram-Positive Bacteria. Acta Microbiol. Immunol. Hung. 2017, 64, 439-453. [CrossRef]

25. Suntharalingam, P.; Cvitkovitch, D.G. Quorum Sensing in Streptococcal Biofilm Formation. Trends Microbiol. 2005, 13, 3-6. [CrossRef] [PubMed]

26. Waters, C.M.; Bassler, B.L. Quorum Sensing: Cell-to-Cell Communication in Bacteria. Annu. Rev. Cell Dev. Biol. 2005, 21, 319-346. [CrossRef]

27. Lin, Y.; Zhou, X.; Li, Y. Strategies for Streptococcus mutans biofilm dispersal through extracellular polymeric substances disruption Mol. Oral Microbiol. 2021, 37, 1-8. [CrossRef] [PubMed]

28. Zhao, X.; Yu, Z.; Ding, T. Quorum-Sensing Regulation of Antimicrobial Resistance in Bacteria. Microorganisms $2020,8,425$. [CrossRef]

29. Pumbwe, L.; Skilbeck, C.A.; Wexler, H.M. Presence of Quorum-Sensing Systems Associated with Multidrug Resistance and Biofilm Formation in Bacteroides fragilis. Microb. Ecol. 2008, 56, 412-419. [CrossRef]

30. Maseda, H.; Sawada, I.; Saito, K.; Uchiyama, H.; Nakae, T.; Nomura, N. Enhancement of the MexAB-OprM Efflux Pump Expression by a Quorum-Sensing Autoinducer and Its Cancellation by a Regulator, MexT, of the MexEF-OprN Efflux Pump Operon in Pseudomonas aeruginosa. Antimicrob. Agents Chemother. 2004, 48, 1320-1328. [CrossRef]

31. Munita, J.M.; Arias, C.A. Mechanisms of antibiotic resistance. Microbiol. Spectr. 2016, 4, 2-4. [CrossRef] [PubMed]

32. Cirou, A.; Diallo, S.; Kurt, C.; Latour, X.; Faure, D. Growth Promotion of Quorum-Quenching Bacteria in the Rhizosphere of Solanum tuberosum. Environ. Microbiol. 2007, 9, 1511-1522. [CrossRef]

33. Jafra, S.; Przysowa, J.; Czajkowski, R.; Michta, A.; Garbeva, P.; Van Der Wolf, J.M. Detection and Characterization of Bacteria from the Potato Rhizosphere Degrading N-Acyl-Homoserine Lactone. Can. J. Microbiol. 2006, 52, 1006-1015. [CrossRef]

34. Yavuztürk Gül, B.; Koyuncu, I. Assessment of New Environmental Quorum Quenching Bacteria as a Solution for Membrane Biofouling. Process. Biochem. 2017, 61, 137-146. [CrossRef]

35. Dong, Y.-H.; Gusti, A.R.; Zhang, Q.; Xu, J.-L.; Zhang, L.-H. Identification of Quorum-Quenching N-Acyl Homoserine Lactonases from Bacillus Species. Appl. Environ. Microbiol. 2002, 68, 1754-1759. [CrossRef]

36. Kumar, P.; Dubey, R.C.; Maheshwari, D.K. Bacillus Strains Isolated from Rhizosphere Showed Plant Growth Promoting and Antagonistic Activity against Phytopathogens. Microbiol. Res. 2012, 167, 493-499. [CrossRef] [PubMed]

37. Moore, T. Antagonistic Activity of Bacillus Bacteria against Food-Borne Pathogens. J. Probiotics Health 2013, 1, 110. [CrossRef]

38. Olishevska, S.; Nickzad, A.; Déziel, E. Bacillus and Paenibacillus Secreted Polyketides and Peptides Involved in Controlling Human and Plant Pathogens. Appl. Microbiol. Biotechnol. 2019, 103, 1189-1215. [CrossRef] [PubMed]

39. Anandan, K.; Vittal, R.R. Quorum Quenching Activity of AiiA Lactonase KMMI17 from Endophytic Bacillus Thuringiensis KMCL07 on AHL-Mediated Pathogenic Phenotype in Pseudomonas aeruginosa. Microb. Pathog. 2019, 132, 230-242. [CrossRef] 
40. Hartmann, A.; Rothballer, M. Role of Quorum Sensing Signals of Rhizobacteria for Plant Growth Promotion. In Rhizotrophs: Plant Growth Promotion to Bioremediation; Mehnaz, S., Ed.; Springer: Singapore, 2017. [CrossRef]

41. Hartmann, A.; Rothballer, M.; Hense, B.A.; Schröder, P. Bacterial Quorum Sensing Compounds Are Important Modulators of Microbe-Plant Interactions. Front. Plant Sci. 2014, 5, 131. [CrossRef]

42. Schikora, A.; Schenk, S.T.; Hartmann, A. Beneficial Effects of Bacteria-Plant Communication Based on Quorum Sensing Molecules of TheN-Acyl Homoserine Lactone Group. Plant Mol. Biol. 2016, 90, 605-612. [CrossRef]

43. Schneider, J.; Yepes, A.; Garcia-Betancur, J.C.; Westedt, I.; Mielich, B.; López, D. Streptomycin-Induced Expression in Bacillus subtilis of YtnP, a Lactonase-Homologous Protein That Inhibits Development and Streptomycin Production in Streptomyces griseus. Appl. Environ. Microbiol. 2012, 78, 599-603. [CrossRef]

44. McBride, S.G.; Strickland, M.S. Quorum Sensing Modulates Microbial Efficiency by Regulating Bacterial Investment in Nutrient Acquisition Enzymes. Soil Biol. Biochem. 2019, 136, 107514. [CrossRef]

45. Nithya, C.; Aravindraja, C.; Pandian, S.K. Bacillus pumilus of Palk Bay Origin Inhibits Quorum-Sensing-Mediated Virulence Factors in Gram-Negative Bacteria. Res. Microbiol. 2010, 161, 293-304. [CrossRef] [PubMed]

46. Chu, W.; Lu, F.; Zhu, W.; Kang, C. Isolation and Characterization of New Potential Probiotic Bacteria Based on Quorum-Sensing System: AHLs-Degrading Bacteria as Probiotic Candidate Isolated from Fish Gut. J. Appl. Microbiol. 2011, 110, 202-208. [CrossRef]

47. Piewngam, P.; Zheng, Y.; Nguyen, T.H.; Dickey, S.W.; Joo, H.-S.; Villaruz, A.E.; Glose, K.A.; Fisher, E.L.; Hunt, R.L.; Li, B.; et al Pathogen Elimination by Probiotic Bacillus via Signalling Interference. Nature 2018, 562, 532-537. [CrossRef]

48. Gunaratnam, S.; Millette, M.; McFarland, L.V.; DuPont, H.L.; Lacroix, M. Potential Role of Probiotics in Reducing Clostridioides difficile Virulence: Interference with Quorum Sensing Systems. Microb. Pathog. 2021, 153, 104798. [CrossRef]

49. Algburi, A.; Zehm, S.; Netrebov, V.; Bren, A.B.; Chistyakov, V.; Chikindas, M.L. Subtilosin Prevents Biofilm Formation by Inhibiting Bacterial Quorum Sensing. Probiotics Antimicrob. Proteins 2017, 9, 81-90. [CrossRef] [PubMed]

50. Colegio, O.R.; Chu, N.-Q.; Szabo, A.L.; Chu, T.; Rhebergen, A.M.; Jairam, V.; Cyrus, N.; Brokowski, C.E.; Eisenbarth, S.C.; Phillips, G.M.; et al. Functional Polarization of Tumour-Associated Macrophages by Tumour-Derived Lactic Acid. Nature 2014, 513, 559-563. [CrossRef] [PubMed]

51. Kim, J.; Kim, J.; Kim, Y.; Oh, S.; Song, M.; Choe, J.H.; Whang, K.-Y.; Kim, K.H.; Oh, S. Influences of Quorum-Quenching Probiotic Bacteria on the Gut Microbial Community and Immune Function in Weaning Pigs. Anim. Sci. J. 2018, 89, 412-422. [CrossRef]

52. Kim, A.-L.; Park, S.-Y.; Lee, C.-H.; Lee, C.-H.; Lee, J.-K. Quorum Quenching Bacteria Isolated from the Sludge of a Wastewater Treatment Plant and Their Application for Controlling Biofilm Formation. J. Microbiol. Biotechnol. 2014, 24, 1574-1582. [CrossRef]

53. Kim, Y.; Lee, J.W.; Kang, S.-G.; Oh, S.; Griffiths, M.W. Bifidobacterium Spp. Influences the Production of Autoinducer-2 and Biofilm Formation by Escherichia coli O157:H7. Anaerobe 2012, 18, 539-545. [CrossRef]

54. Kampouris, I.D.; Karayannakidis, P.D.; Banti, D.C.; Sakoula, D.; Konstantinidis, D.; Yiangou, M.; Samaras, P.E. Evaluation of a Novel Quorum Quenching Strain for MBR Biofouling Mitigation. Water Res. 2018, 143, 56-65. [CrossRef] [PubMed]

55. Li, J.; Wang, W.; Xu, S.X.; Magarvey, N.A.; McCormick, J.K. Lactobacillus reuteri-Produced Cyclic Dipeptides Quench Agr-Mediated Expression of Toxic Shock Syndrome Toxin-1 in Staphylococci. Proc. Natl. Acad Sci. USA 2011, 108, 3360-3365. [CrossRef] [PubMed]

56. Li, T.; Cui, F.; Bai, F.; Zhao, G.; Li, J. Involvement of Acylated Homoserine Lactones (AHLs) of Aeromonas sobria in Spoilage of Refrigerated Turbot (Scophthalmus maximus L.). Sensors 2016, 16, 1083. [CrossRef] [PubMed]

57. Morohoshi, T.; Fukamachi, K.; Kato, M.; Kato, N.; Ikeda, T. Regulation of the Violacein Biosynthetic Gene Cluster by Acylhomoserine Lactone-Mediated Quorum Sensing in Chromobacterium violaceum ATCC 12472. Biosci. Biotechnol. Biochem. 2010, 74, 2116-2119. [CrossRef]

58. Cui, T.; Bai, F.; Sun, M.; Lv, X.; Li, X.; Zhang, D.; Du, H. Lactobacillus crustorum ZHG 2-1 as Novel Quorum-Quenching Bacteria Reducing Virulence Factors and Biofilms Formation of Pseudomonas aeruginosa. LWT 2020, 117, 108696. [CrossRef]

59. Rana, S.; Bhawal, S.; Kumari, A.; Kapila, S.; Kapila, R. PH-Dependent Inhibition of AHL-Mediated Quorum Sensing by Cell-Free Supernatant of Lactic Acid Bacteria in Pseudomonas aeruginosa PAO1. Microb. Pathog. 2020, 142, 104105. [CrossRef]

60. Dong, W.; Zhu, J.; Guo, X.; Kong, D.; Zhang, Q.; Zhou, Y.; Liu, X.; Zhao, S.; Ruan, Z. Characterization of AiiK, an AHL Lactonase, from Kurthia huakui LAM0618T and Its Application in Quorum Quenching on Pseudomonas aeruginosa PAO1. Sci. Rep. 2018, 8, 6013. [CrossRef]

61. Wang, L.-H.; Weng, L.-X.; Dong, Y.-H.; Zhang, L.-H. Specificity and Enzyme Kinetics of the Quorum-Quenching N-Acyl Homoserine Lactone Lactonase (AHL-Lactonase). J. Biol. Chem. 2004, 279, 13645-13651. [CrossRef]

62. Yates, E.A.; Philipp, B.; Buckley, C.; Atkinson, S.; Chhabra, S.R.; Sockett, R.E.; Goldner, M.; Dessaux, Y.; Cámara, M.; Smith, H.; et al. $\mathrm{N}-$ Acylhomoserine Lactones Undergo Lactonolysis in a PH-, Temperature-, and Acyl Chain Length-Dependent Manner during Growth of Yersinia pseudotuberculosis and Pseudomonas aeruginosa. Infect. Immun. 2002, 70, 5635-5646. [CrossRef]

63. Li, X.-Z.; Plésiat, P.; Nikaido, H. The Challenge of Efflux-Mediated Antibiotic Resistance in Gram-Negative Bacteria. Clin. Microbiol. Rev. 2015, 28, 337-418. [CrossRef]

64. Yan, X.; Gu, S.; Cui, X.; Shi, Y.; Wen, S.; Chen, H.; Ge, J. Antimicrobial, Anti-Adhesive and Anti-Biofilm Potential of Biosurfactants Isolated from Pediococcus acidilactici and Lactobacillus plantarum against Staphylococcus Aureus CMCC26003. Microb. Pathog. 2019, 127, 12-20. [CrossRef] [PubMed] 
65. Hossain, M.I.; Mizan, M.F.R.; Roy, P.K.; Nahar, S.; Toushik, S.H.; Ashrafudoulla, M.; Jahid, I.K.; Lee, J.; Ha, S.-D. Listeria monocytogenes Biofilm Inhibition on Food Contact Surfaces by Application of Postbiotics from Lactobacillus curvatus B.67 and Lactobacillus plantarum M.2. Food Res. Int. 2021, 148, 110595. [CrossRef]

66. Yong, C.C.; Lim, J.; Kim, B.-K.; Park, D.-J.; Oh, S. Suppressive Effect of Lactobacillus fermentum Lim2 on Clostridioides Difficile 027 Toxin Production. Lett. Appl. Microbiol. 2019, 68, 386-393. [CrossRef] [PubMed]

67. Lv, X.; Cui, T.; Du, H.; Sun, M.; Bai, F.; Li, J.; Zhang, D. Lactobacillus plantarum CY 1-1: A Novel Quorum Quenching Bacteria and Anti-Biofilm Agent against Aeromonas sobria. LWT 2021, 137, 110439. [CrossRef]

68. Selvakumar, G.; Panneerselvam, P.; Ganeshamurthy, A.N. Diversity Utility and Potential of Actinobacteria in the Agro-Ecosystem. In Bacterial Diversity in Sustainable Agriculture; Sustainable Development and Biodiversity; Maheshwari, D.K., Ed.; Springer International Publishing: Berlin/Heidelberg, Germany, 2014; pp. 23-40. [CrossRef]

69. Recio, E.; Colinas, Á.; Rumbero, Á.; Aparicio, J.F.; Martín, J.F. PI Factor, a Novel Type Quorum-Sensing Inducer Elicits Pimaricin Production in Streptomyces natalensis. J. Biol. Chem. 2004, 279, 41586-41593. [CrossRef]

70. Vesuna, A.P.; Nerurkar, A.S. Biocontrol Impact of AHL Degrading Actinobacteria on Quorum Sensing Regulated Virulence of Phytopathogen Pectobacterium carotovorum subsp. carotovorum BR1. Plant Soil 2020, 453, 371-388. [CrossRef]

71. Weber, T.; Welzel, K.; Pelzer, S.; Vente, A.; Wohlleben, W. Exploiting the Genetic Potential of Polyketide Producing Streptomycetes. J. Biotechnol. 2003, 106, 221-232. [CrossRef]

72. Wijaya, M.; Delicia, D.; Waturangi, D.E. Screening and Quantification of Antiquorum-Sensing Activity of Actinobacteria Isolates Against Gram-Positive and Gram-Negative Biofilm Associated Bacteria. Res. Sq. 2021, 1-2, 1. [CrossRef]

73. Mulya, E.; Waturangi, D.E. Screening and Quantification of Anti-Quorum Sensing and Antibiofilm Activity of Actinomycetes Isolates against Food Spoilage Biofilm-Forming Bacteria. BMC Microbiol. 2021, 21, 52. [CrossRef] [PubMed]

74. Chankhamhaengdecha, S.; Hongvijit, S.; Srichaisupakit, A.; Charnchai, P.; Panbangred, W. Endophytic Actinomycetes: A Novel Source of Potential Acyl Homoserine Lactone Degrading Enzymes. BioMed Res. Int. 2013, 2013, e782847. [CrossRef]

75. Park, S.-Y.; Kang, H.-O.; Jang, H.-S.; Lee, J.-K.; Koo, B.-T.; Yum, D.-Y. Identification of Extracellular N-Acylhomoserine Lactone Acylase from a Streptomyces sp. and Its Application to Quorum Quenching. Appl. Environ. Microbiol. 2005, 71, $2632-2641$. [CrossRef]

76. Wang, W.-Z.; Morohoshi, T.; Ikenoya, M.; Someya, N.; Ikeda, T. AiiM, a Novel Class of N-Acylhomoserine Lactonase from the Leaf-Associated Bacterium Microbacterium testaceum. Appl. Environ. Microbiol. 2010, 76, 2524-2530. [CrossRef] [PubMed]

77. Devaraj, K.; Tan, G.Y.A.; Chan, K.-G. Quorum Quenching Properties of Actinobacteria Isolated from Malaysian Tropical Soils. Arch Microbiol. 2017, 199, 897-906. [CrossRef]

78. Junji, I.; Hideo, T.; Haruo, I.; Satoshi, O. Cloning and Sequencing of the Aculeacin a Acylase-Encoding Gene from Actinoplanes Utahensis and Expression in Streptomyces lividans. Gene 1992, 119, 29-35. [CrossRef]

79. Park, S.-Y.; Lee, S.J.; Oh, T.-K.; Oh, J.-W.; Koo, B.-T.; Yum, D.-Y.; Lee, J.-K. AhlD, an N-Acylhomoserine Lactonase in Arthrobacter sp., and Predicted Homologues in Other Bacteria. Microbiology 2003, 149, 1541-1550. [CrossRef]

80. Naik, D.N.; Wahidullah, S.; Meena, R.M. Attenuation of Pseudomonas aeruginosa Virulence by Marine Invertebrate-Derived Streptomyces sp. Lett. Appl. Microbiol. 2013, 56, 197-207. [CrossRef] [PubMed]

81. Koul, S.; Kalia, V.C. Multiplicity of Quorum Quenching Enzymes: A Potential Mechanism to Limit Quorum Sensing Bacterial Population. Indian J. Microbiol. 2017, 57, 100-108. [CrossRef] [PubMed]

82. Cirou, A.; Mondy, S.; An, S.; Charrier, A.; Sarrazin, A.; Thoison, O.; DuBow, M.; Faure, D. Efficient Biostimulation of Native and Introduced Quorum-Quenching Rhodococcus erythropolis Populations Is Revealed by a Combination of Analytical Chemistry, Microbiology, and Pyrosequencing. Appl. Environ. Microbiol. 2012, 78, 481-492. [CrossRef]

83. Uroz, S.; Oger, P.M.; Chapelle, E.; Adeline, M.-T.; Faure, D.; Dessaux, Y. A Rhodococcus QsdA-Encoded Enzyme Defines a Novel Class of Large-Spectrum Quorum-Quenching Lactonases. Appl. Environ. Microbiol. 2008, 74, 1357-1366. [CrossRef]

84. Uroz, S.; Chhabra, S.R.; Cámara, M.; Williams, P.; Oger, P.; Dessaux, Y. N-Acylhomoserine Lactone Quorum-Sensing Molecules Are Modified and Degraded by Rhodococcus erythropolis W2 by Both Amidolytic and Novel Oxidoreductase Activities. Microbiology 2005, 151, 3313-3322. [CrossRef]

85. Barbey, C.; Chane, A.; Burini, J.-F.; Maillot, O.; Merieau, A.; Gallique, M.; Beury-Cirou, A.; Konto-Ghiorghi, Y.; Feuilloley, M.; Gobert, V.; et al. A Rhodococcal Transcriptional Regulatory Mechanism Detects the Common Lactone Ring of AHL QuorumSensing Signals and Triggers the Quorum-Quenching Response. Front. Microbiol. 2018, 9, 2800. [CrossRef] [PubMed]

86. Harper, D.R.; Parracho, H.M.R.T.; Walker, J.; Sharp, R.; Hughes, G.; Werthén, M.; Lehman, S.; Morales, S. Bacteriophages and Biofilms. Antibiotics 2014, 3, 270-284. [CrossRef]

87. Drucker, V.V.; Gorshkova, A.S. Bacteriophages and their functioning in the biofilms. Bull. Irkutsk. State Univ. $2012,5,8-16$.

88. Zhou, L.; Zhang, Y.; Ge, Y.; Zhu, X.; Pan, J. Regulatory Mechanisms and Promising Applications of Quorum Sensing-Inhibiting Agents in Control of Bacterial Biofilm Formation. Front. Microbiol. 2020, 11, 589640. [CrossRef] [PubMed]

89. Villa, T.G.; Feijoo-Siota, L.; Rama, J.R.; Sánchez-Pérez, A.; Viñas, M. Horizontal Gene Transfer Between Bacteriophages and Bacteria: Antibiotic Resistances and Toxin Production. In Horizontal Gene Transfer; Villa, T.G., Viñas, M., Eds.; Springer International Publishing: Cham, Switzerland, 2019; pp. 97-142. [CrossRef]

90. Chu, Y.-Y.; Nega, M.; Wölfle, M.; Plener, L.; Grond, S.; Jung, K.; Götz, F. A New Class of Quorum Quenching Molecules from Staphylococcus Species Affects Communication and Growth of Gram-Negative Bacteria. PLoS Pathog. 2013, 9, e1003654. [CrossRef] [PubMed] 
91. Kalia, V.C.; Raju, S.C.; Purohit, H.J. Genomic analysis reveals versatile organisms for quorum quenching enzymes: Acylhomoserine lactone-acylase and -lactonase. Open Microbiol. J. 2011, 5, 1-13. [CrossRef]

92. Goh, S.Y.; Khan, S.A.; Tee, K.K.; Kasim, N.H.A.; Yin, W.F.; Chan, K.G. Quorum sensing activity of Citrobacter amalonaticus L8A, a bacterium isolated from dental plaque. Sci. Rep. 2016, 6, 20702. [CrossRef]

93. Li, Y.-S.; Tian, T.; Li, B.-B.; Yu, H.-Q. Longer Persistence of Quorum Quenching Bacteria over Quorum Sensing Bacteria in Aerobic Granules. Water Res. 2020, 179, 115904. [CrossRef]

94. Dong, Y.-H.; Wang, L.-H.; Xu, J.-L.; Zhang, H.-B.; Zhang, X.-F.; Zhang, L.-H. Quenching Quorum-Sensing-Dependent Bacterial Infection by an N-Acyl Homoserine Lactonase. Nature 2001, 411, 813-817. [CrossRef]

95. Cao, Y.; He, S.; Zhou, Z.; Zhang, M.; Mao, W.; Zhang, H.; Yao, B. Orally Administered Thermostable N-Acyl Homoserine Lactonase from Bacillus Sp. Strain AI96 Attenuates Aeromonas hydrophila Infection in Zebrafish. Appl. Environ. Microbiol. 2012, 78, 1899-1908. [CrossRef]

96. Fong, J.; Zhang, C.; Yang, R.; Boo, Z.Z.; Tan, S.K.; Nielsen, T.E.; Givskov, M.; Liu, X.-W.; Bin, W.; Su, H.; et al. Combination Therapy Strategy of Quorum Quenching Enzyme and Quorum Sensing Inhibitor in Suppressing Multiple Quorum Sensing Pathways of P. aeruginosa. Sci. Rep. 2018, 8, 1155. [CrossRef] [PubMed]

97. Kalia, V.C.; Kumar, P.; Pandian, S.K.T.; Sharma, P. Biofouling Co 15. Biofouling Control by Quorum Quenching; Springer: Berlin/Heidelberg, Germany, 2015; pp. 431-440. [CrossRef]

98. Algburi, A.; Comito, N.; Kashtanov, D.; Dicks, L.M.T.; Chikindas, M.L. Control of Biofilm Formation: Antibiotics and Beyond. Appl. Environ. Microbiol. 2017, 83, e02508-16. [CrossRef] [PubMed]

99. Mann, A.; Nehra, K.; Rana, J.S.; Dahiya, T. Antibiotic resistance in agriculture: Perspectives on upcoming strategies to overcome upsurge in resistance. Curr. Res. Microb. Sci. 2021, 2, 100030. [CrossRef] [PubMed]

100. Gorovtsov, A.V.; Sazykin, I.S.; Sazykina, M.A. The influence of heavy metals, polyaromatic hydrocarbons, and polychlorinated biphenyls pollution on the development of antibiotic resistance in soils. Environ. Sci. Pollut. Res. 2018, 25, 9283-9292. [CrossRef]

101. Garge, S.S.; Nerurkar, A.S. Evaluation of Quorum Quenching Bacillus Spp. for Their Biocontrol Traits against Pectobacterium carotovorum Subsp. Carotovorum Causing Soft Rot. Biocatal. Agric. Biotechnol. 2017, 9, 48-57. [CrossRef]

102. Beckmann, B.E.; Knoester, D.B.; Connelly, B.D.; Waters, C.M.; McKinley, P.K. Evolution of Resistance to Quorum Quenching in Digital Organisms. Artif. Life 2012, 18, 291-310. [CrossRef]

103. Hill, C.; Guarner, F.; Reid, G.; Gibson, G.R.; Merenstein, D.J.; Pot, B.; Morelli, L.; Canani, R.B.; Flint, H.J.; Salminen, S. The International Scientific Association for Probiotics and Prebiotics Consensus Statement on the Scope and Appropriate Use of the Term Probiotic. Nat. Rev. Gastroenterol. Hepatol. 2014, 11, 506-514. [CrossRef]

104. Demin, K.A.; Refeld, A.G.; Bogdanova, A.A.; Prazdnova, E.V.; Popov, I.V.; Kutsevalova, O.Y.; Ermakov, A.M.; Bren, A.B.; Rudoy, D.V.; Chistyakov, V.A.; et al. Mechanisms of Candida Resistance to Antimycotics and Promising Ways to Overcome It: The Role of Probiotics. Probiotics Antimicrob. Proteins 2021, 13, 926-948. [CrossRef]

105. Dong, Y.-H.; Wang, L.-H.; Zhang, L.-H. Quorum-Quenching Microbial Infections: Mechanisms and Implications. Philos. Trans. R. Soc. B 2007, 362, 1201-1211. [CrossRef]

106. Zhou, S.; Yu, Z.; Chu, W. Effect of Quorum-Quenching Bacterium Bacillus sp. QSI-1 on Protein Profiles and Extracellular Enzymatic Activities of Aeromonas hydrophila YJ-1. BMC Microbiol. 2019, 19, 135. [CrossRef]

107. Chu, W.; Zhou, S.; Zhu, W.; Zhuang, X. Quorum Quenching Bacteria Bacillus sp. QSI-1 Protect Zebrafish (Danio Rerio) from Aeromonas hydrophila Infection. Sci. Rep. 2014, 4, 5446. [CrossRef]

108. Chen, B.; Peng, M.; Tong, W.; Zhang, Q.; Song, Z. The Quorum Quenching Bacterium Bacillus licheniformis T-1 Protects Zebrafish against Aeromonas hydrophila Infection. Probiotics Antimicrob. Proteins 2020, 12, 160-171. [CrossRef]

109. Ghanei-Motlagh, R.; Mohammadian, T.; Gharibi, D.; Menanteau-Ledouble, S.; Mahmoudi, E.; Khosravi, M.; Zarea, M.; ElMatbouli, M. Quorum Quenching Properties and Probiotic Potentials of Intestinal Associated Bacteria in Asian Sea Bass Lates calcarifer. Mar. Drugs 2019, 18, 23. [CrossRef] [PubMed]

110. Ghanei-Motlagh, R.; Gharibi, D.; Mohammadian, T.; Khosravi, M.; Mahmoudi, E.; Zarea, M.; Menanteau-Ledouble, S.; ElMatbouli, M. Feed Supplementation with Quorum Quenching Probiotics with Anti-Virulence Potential Improved Innate Immune Responses, Antioxidant Capacity and Disease Resistance in Asian Seabass (Lates calcarifer). Aquaculture 2021, 535, 736345. [CrossRef]

111. Kiarood, S.L.A.; Rahnama, K.; Golmohammadi, M.; Nasrollanejad, S. Quorum-Quenching Endophytic Bacteria Inhibit Disease Caused by Pseudomonas syringae Pv. Syringae in Citrus Cultivars. J. Basic Microbiol. 2020, 1, 12. [CrossRef]

112. Valdéz, J.C.; Peral, M.C.; Rachid, M.; Santana, M.; Perdigón, G. Interference of Lactobacillus Plantarum with Pseudomonas aeruginosa in Vitro and in Infected Burns: The Potential Use of Probiotics in Wound Treatment. Clin. Microbiol. Infect. 2005, 11, 472-479. [CrossRef] [PubMed]

113. Vadassery, D.H.; Pillai, D. Quorum Quenching Potential of Enterococcus faecium QQ12 Isolated from Gastrointestinal Tract of Oreochromis Niloticus and Its Application as a Probiotic for the Control of Aeromonas hydrophila Infection in Goldfish Carassius auratus (Linnaeus 1758). Braz. J. Microbiol. 2020, 51, 1333-1343. [CrossRef] [PubMed]

114. Wasfi, R.; Abd El-Rahman, O.A.; Zafer, M.M.; Ashour, H.M. Probiotic Lactobacillus sp. Inhibit Growth, Biofilm Formation and Gene Expression of Caries-Inducing Streptococcus mutans. J. Cell. Mol. Med. 2018, 22, 1972-1983. [CrossRef]

115. Méndez-Vilas, A. Industrial, Medical and Environmental Applications of Microorganisms: Current Status and Trends; Wageningen Academic Publishers: Wageningen, The Netherlands, 2014; Volume 698. [CrossRef] 
116. Dong, Y.-H.; Xu, J.-L.; Li, X.-Z.; Zhang, L.-H. AiiA, an Enzyme That Inactivates the Acylhomoserine Lactone Quorum-Sensing Signal and Attenuates the Virulence of Erwinia carotovora. Proc. Natl. Acad. Sci. USA 2000, 97, 3526-3531. [CrossRef]

117. Carlier, A.; Uroz, S.; Smadja, B.; Fray, R.; Latour, X.; Dessaux, Y.; Faure, D. The Ti Plasmid of Agrobacterium tumefaciens Harbors an AttM-Paralogous Gene, AiiB, Also Encoding N-Acyl Homoserine Lactonase Activity. Appl. Environ. Microbiol. 2003, 69, 4989-4993. [CrossRef]

118. Molina, L.; Rezzonico, F.; Défago, G.; Duffy, B. Autoinduction in Erwinia amylovora: Evidence of an Acyl-Homoserine Lactone Signal in the Fire Blight Pathogen. J. Bacteriol. 2005, 187, 3206-3213. [CrossRef]

119. Dong, Y.-H.; Zhang, X.-F.; Xu, J.-L.; Zhang, L.-H. Insecticidal Bacillus Thuringiensis Silences Erwinia carotovora Virulence by a New Form of Microbial Antagonism, Signal Interference. Appl. Environ. Microbiol. 2004, 70, 954-960. [CrossRef] [PubMed]

120. Alinejad, F.; Shahryari, F.; Eini, O.; Sarafraz-Niko, F.; Shekari, A.; Setareh, M. Screening of Quorum-Quenching Bacteria Associated with Rhizosphere as Biocontrol Agents of Pectobacterium carotovorum subsp. Carotovorum. Arch. Phytopathol 2020, 53, 509-523. [CrossRef]

121. Zamani, M.; Behboudi, K.; Ahmadzadeh, M. Quorum Quenching by Bacillus cereus U92: A Double-Edged Sword in Biological Control of Plant Diseases. Biocontrol Sci. Technol. 2013, 23, 555-573. [CrossRef] 